\title{
Anti-Neuroinflammatory and Neurotrophic Effects of Combined Therapy with Annexin II and Reg-2 on Injured Spinal Cord
}

\author{
Marong Fang ${ }^{a} \quad$ Jian-Ying Huang ${ }^{a} \quad$ Jing Wang ${ }^{a}$ Shu-Cai Ling ${ }^{a} \quad$ John A. Rudd ${ }^{b}$ \\ Zhi-Ying Huc Lin-Hao Xu ${ }^{a}$ Zhang-Gen Yuan ${ }^{d}$ Shu Han ${ }^{a}$

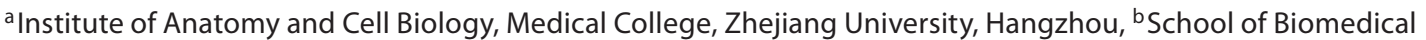 \\ Sciences, Faculty of Medicine, The Chinese University of Hong Kong, Hong Kong, 'Department of Obstetrics and \\ Gynecology, Hangzhou Red Cross Hospital, and ${ }^{d}$ Institute of Anatomy, Zhejiang University City College, \\ Hangzhou, China
}

\section{Key Words}

Annexin II $\cdot$ Reg-2 protein $\cdot$ Spinal cord injury $\cdot$ White matter sparing $\cdot$ Neuroprotective effects

\begin{abstract}
The present study was designed to investigate the neuroprotective effects of $\mathrm{Ca}^{2+}$-dependent phospholipid-binding protein annexin II and a secreted protein Reg-2 (regeneration gene protein 2 ) in spinal cord injury ( $\mathrm{SCl}$ ) model produced by contusion $\mathrm{SCl}_{\text {at }} \mathrm{T}_{9}$ using the weight drop method. The agents were delivered intrathecally with Alzet miniosmotic pumps. We found that annexin II and Reg-2 remarkably reduced neuronal death, attenuated tissue damage and alleviated detrimental inflammation in vivo; meanwhile, a significant increase in white matter sparing and myelination area was observed. The propriospinal axons and long-distance supraspinal pathways were protected by the treatments as revealed by retrograde tracing. Basso Beattie Bresnahan locomotor rating scores also revealed a measurable behavioral improvement. However, no evident behavioral improvements in locomotor performance were achieved by the combined treatment with annexin II and Reg-2, compared with the separate treatment with annexin II and Reg-2.
\end{abstract}

Copyright ๑ 2011 S. Karger AG, Basel
(C) 2011 S. Karger AG, Basel

$1424-862 X / 11 / 0191-0016 \$ 38.00 / 0$

Fax +4161306 1234

E-Mail karger@karger.ch

www.karger.com
Accessible online at:

www.karger.com/nsg

\section{Introduction}

Annexin is a superfamily of calcium- and phospholipid-binding proteins. Its expression increases in the central nervous system (CNS) during the course of embryo's development, then gradually declines and disappears during early postnatal development stage $[1,2]$. Under some pathological conditions, i.e. traumatic hemorrhage, embolism, and thrombotic infarction or some diseases of the CNS, such as encephalomyelitis and Alzheimer disease, its expression is reupregulated $[3,4]$.

The posttraumatic inflammatory reaction contributes to progressive tissue damage after CNS disease or injury. Subsequent researches have shown that annexins are involved in multiple biologic functions ranging from intracellular events like signal transduction to extracellular events which may affect inflammation [5-7]. The annexin superfamily consists of at least 94 distinct proteins [8]. It has been demonstrated that three members of this family, annexins I, II, and V, could exert potent anti-inflammatory effects [9-12]. Previous studies showed that the expression of annexins I, II, V increased in the spinal cord tissue adjacent to the transection [13] or the contusion [14] region, and it is believed that these annexins exert anti-inflammatory actions through the inhibition of 
$\mathrm{PLA}_{2}$ activity $[5,15]$, a key enzyme responsible for inflammation and cytotoxicity [16-17]. An anti-inflammatory effect of annexin I was confirmed in vitro; furthermore, neurotrophic effects of annexins I and V on cultured neurons were also revealed [18-20]; however, the effects of annexin II on posttraumatic insults remain unclear.

Reg-2 is a $16-\mathrm{kDa}$ secreted protein belonging to a family of similar proteins, structurally related to c-type lectins, upregulated in pancreatitis, and exerting an antiapoptotic action on pancreatic cell lines [21-23]. Similar to annexins, Reg-2 is not expressed either in the CNS of adult rat, or the peripheral nervous system (PNS); it can be expressed in both sensory and motor neurons during the development stage [24]. It is strongly upregulated in PNS after nerve axotomy or crushing in adult rat, and reexpressed in the CNS in the case of Alzheimer's disease, inflammation and spinal cord injury (SCI) [25-29]. Following injury, the expression of Reg-2 is upregulated mainly in motor and sensory neurons, and undetectable in oligodendrocytes and astrocytes [29]. However, the expression of annexin II was increased not only in motor and sensory neurons, but also in various inflammatory cells, astrocytes and oligodendrocytes [14].

In our previous studies, the in vitro effects of annexin II and Reg-2 on survival of spinal cord neurons were investigated. Our results confirmed that blocking endogenous annexin II and Reg-2 expression with specific antibodies in cultured embryonic neurons could lead to a significant reduction in neuronal survival and neurite outgrowth [29-30]; meanwhile, annexin II blockage also affected the survival of astrocytes cultured. Moreover, a remarkable reduction in LDH release and cell death in both cell peroxide and hypoxia injury models was shown with the application of annexin II and Reg-2 on various cell injury models [29-30]; therefore, a protective reupregulation of annexin II and Reg-2 expression following injury is proposed. To prove this hypothesis, the present study was designed to determine their effects in vivo using an adult rat weight drop contusion model on the 9th thoracic level.

In SCI models, intracerebroventricular application of drugs and intrathecal infusion have shown better effects than intravenous or local injection [31-32]. To maintain dose consistency in long-term drug delivery, the agents were delivered intrathecally with implantable Alzet osmotic pumps, and the in vivo effects were compared with saline vehicle. Optimal dosage was adapted based on our previous experiments of dose response in vivo [33]. Multiple histological and immunohistochemical staining,
Fluorogold (FG) retrograde tracing, and BBB locomotor rating scale were employed to assess white matter sparing, myelination, inflammation, long-tract axonal protection and functional recovery in rats with SCI.

\section{Materials and Methods}

\section{Animals}

A total of 153 adult female Sprague-Dawley rats weighing 250$300 \mathrm{~g}$ were used. Five rats were used as sham group, the other 148 rats were randomly assigned to 4 SCI groups, treated with (1) saline vehicle (200 $\mu$ l, i.t.), (2) annexin II protein (Biodesign International, New York, $100 \mu$ g, i.t.), (3) Reg-2 protein (genway, San Diego, Calif., USA, $500 \mu$ g, i.t.), and (4) $100 \mu$ g annexin II + 500 $\mu \mathrm{g}$ Reg-2 protein (A+R group, i.t.). The animals of each group survived for $24 \mathrm{~h}(\mathrm{n}=11), 7$ days $(\mathrm{n}=11)$ and 42 days $(\mathrm{n}=15)$ after SCI. Drugs were delivered continually via implantation of an Alzet osmotic minipump over $24 \mathrm{~h}(\mathrm{n}=44$, pump model 2001D; $8.0 \mu \mathrm{l} / \mathrm{h}$; Alza Corp., Palo Alto, Calif., USA) and 7 days $(\mathrm{n}=104$, pump model 2001; $1.0 \mu \mathrm{l} / \mathrm{h}$ ).

\section{Surgical Procedures and Drug Delivery}

Before surgery, osmotic minipumps were prepared under sterile conditions and filled with $0.9 \%$ saline vehicle, annexin II and/ or Reg-2 protein in saline. Cannulae consisting of polyurethane tubing were sterilized overnight in $100 \%$ ethanol before being attached to the flow moderator of the pump, and the pumps were incubated overnight at room temperature in sterile saline for priming.

The animals were anesthetized with intraperitoneal injections of $1 \%$ Nembutal $(40 \mathrm{mg} / \mathrm{kg})$, and a laminectomy was performed at the $\mathrm{T}_{9}-\mathrm{T}_{10}$ level. The spinal cord of the sham-operated group was exposed but left intact. In other surgery groups, the rat spinal cords were contused with the NYU weight-drop device by dropping the 10-gram rod at a distance of $50 \mathrm{~mm}$, according to methods previously reported by Basso et al. [34]. The catheters were introduced into the subarachnoid space through small holes in the dura at $\mathrm{T}_{12}$, the tips were advanced to $\mathrm{T}_{9}$, and the infusion was performed immediately. The catheter was sutured to the muscles, and the pump was placed in a subcutaneous pocket. The dura was sealed and the wound was closed in layers.

After the surgery, rats were placed in temperature- and humidity-controlled chambers overnight and injected with penicillin intramuscularly for 7 days (25,000 UI per rat, b.i.d.). Manual bladder emptying was performed at least three times daily until reflex bladder emptying was established.

\section{Behavioral Assessment}

A 22-point scale (scores 0-21) of BBB locomotor rating differentiate hindlimb locomotor activity over a wide range of injury ( $n=5$ per group), from a score of 0 , indicative of no observed hindlimb movements, to a score of 21 which is representative of a normal ambulating rodent [34-35]. Prior to surgery, naive rats were individually placed in the center of a circular enclosure made of molded plastic with a smooth, nonslip floor $(90 \mathrm{~cm}$ diameter, 7 $\mathrm{cm}$ wall height) for $4 \mathrm{~min}$ to evaluate the locomotor activities of the trunk, tail, and hind limbs to assure that all subjects consistently obtained a maximum score of 21 . The test was initiated 3 
days after surgery, and then twice a week for 6 weeks, the rats were placed in the open field for $4 \mathrm{~min}$ and scored by observers blinded to the experimental treatments.

\section{FG Retrograde Tracing}

FG (Fluorochrome, Inc., Denver, Colo., USA) retrograde tracing was used to determine the extent to which spared descending axons reached the rostral lumbar enlargement ( $\mathrm{n}=4$ per group). Briefly, 5 weeks after injury, 4\% FG was injected into the lumbar enlargement at $1 \mathrm{~mm}$ from the midline and $1.5 \mathrm{~mm}$ from the dorsal cord surface on both sides $(0.5 \mu$ l per injection) using a glass micropipette attached to a pneumatic picopump which was approximately $12 \mathrm{~mm}$ distal to the lesion epicenter. One week later, rats were sacrificed, transverse sections of $20 \mu \mathrm{m}$ thickness from the $\mathrm{C}_{6}$ and $\mathrm{T}_{5}$ segments were chosen as the representative of cervical and thoracic segments. The number of FG-labeled neurons was counted bilaterally within these two cord segments $(3 \mathrm{~mm}$ in length, every fourth section). For transverse sections from the entire brainstem and sensorimotor cortex, the total number of FGlabeled neurons in nucleus of trigeminal nerve (SPT), the dorsal thalamus (DT), the caudal pontine reticular nucleus (Pnc), the red nucleus (RN), and the hind limb area of motor cortex (Ctx-HL) was counted bilaterally. Only FG-labeled neurons with nuclei were mapped and counted to avoid the duplication of single cells in the count.

\section{Perfusion and Tissue Processing}

Rats were sacrificed at $24 \mathrm{~h}, 1$ week and 6 weeks ( $n=8$ per group) following injury. Animals were given a lethal dose of Nembutal, perfused intracardially with saline and then with $4 \%$ paraformaldehyde in $0.1 \mathrm{M}$ phosphate buffer ( $\mathrm{pH} 7.4)$. The spinal cord and brain tissues were carefully harvested and dissected, fixed in the same fixative for $4 \mathrm{~h}$, then moved into $30 \%$ sucrose in PBS until the tissue dropped to the bottom of the container. Twenty- $\mu \mathrm{m}-$ thick sections were cut on freezing microtome through the horizontal $(n=3)$ and transverse planes $(n=5)$ using a Leica cryostat, then mounted onto $0.02 \%$ poly-L-lysine-coated slides. All sections were collected for histological or immunohistological staining.

The sections from rats sacrificed $24 \mathrm{~h}$ following SCI were prepared for immunohistochemical staining of myeloperoxidase (MPO). From the rats 7 days and 42 days after SCI, one of every eleven of the sections was taken as one set, and eleven sets of sections were processed for: hematoxylin-eosin (HE), cresyl violet, Luxol fast blue (LFB) staining, silver degenerating axons staining described by Eager [36], immunohistochemistry staining for NFM, TNF- $\alpha$, glial fibrillary acidic protein (GFAP) and caspase 3, immunofluorescence labeling for growth-associated protein 43 (GAP-43), CD45 and CD68/ED1.

\section{Histology Assessment}

For measuring the area of the cystic cavity within spinal cord sections, HE staining was used. Five sections in the injury epicenter of each animal were analyzed, images were captured by a Nikon CCD camera, and the cross-sectional area of the cavity was measured using an NIH Image software. The maximal value of cross-sectional area of cavity was selected at each section. Two independent observers made these measurements over the same images, and the final maximum cross-sectional area of the cavity in each animal was considered as the mean value of both observers.
Five transverse sections of each animal were selected for cresyl violet staining at random. The sections were photographed under $\times 400$ magnification using a Nikon TE-300 microscope in 3 vision fields per section; neuronal counts were performed on both anterior horns and restricted to the neurons with a well-defined nucleolus and a cell body rich in endoplasmic reticulum.

Transverse sections from the injury epicenter were also stained for myelin using LFB. Digital photomicrographs were obtained at $\times 40$ magnification and analyzed for spared white matter area using the NIH image software. The injury epicenter was determined for each animal by the rostrocaudal level that contained the least amount of spared myelin per transverse section. The degenerating axons of each section were also identified by Eager's silver staining method.

\section{Immunohistochemical Staining}

The sections were permeabilized and blocked with $0.3 \%$ Triton X-100/10\% normal goat serum in $0.01 \mathrm{M}$ PBS for $30 \mathrm{~min}$, then incubated with polyclonal rabbit antibodies: anti-160KD NF-M (1:1,000, Neuromics, Minneapolis, Minn., USA), anti-TNF- $\alpha$ (1:1,000, ProSci Incorporated, Poway, Calif., USA), anti-caspase 3 (1:500; Cayman Chemical, Ann Arbor, Mich., USA), anti-GFAP (1:200, Thermo Fisher Scientific, Waltham, Mass., USA) overnight at $4^{\circ} \mathrm{C}$. Sections were incubated with secondary biotinylated goat anti-rabbit IgG antibody (1:400; Vector Laboratories, Burlingame, Calif., USA) for $1 \mathrm{~h}$ at room temperature, followed by an avidin-biotin peroxidase complex (ABC kit, Thermo Fisher Scientific, Freemont, Calif., USA). After incubation for 5 min with $0.02 \% \mathrm{DAB}$ and $0.003 \% \mathrm{H}_{2} \mathrm{O}_{2}$ in 0.005 Tris- $\mathrm{HCl}$, the sections were counterstained with hematoxylin. Primary antibody omission controls were used to further confirm the specificity of the immunohistochemical labeling. Five transverse sections of each animal were selected at random and the images were photographed under $\times 200$ magnification in 3 vision fields per section. TNF- $\alpha$ and caspase- 3 immunoreactive cells were counted on preserved anterior horns of each spinal cord section.

\section{Immunofluorescence Labeling}

The sections were pretreated with the same method as described above, incubated with primary polyclonal rabbit anti160KD NF-M primary antibody $(1: 1,000)$, anti-MPO (1:100, Santa Cruz Biotechnology, Calif., USA), anti-GFAP (1:200) and monoclonal antibodies including mouse anti-GAP43, CD45, CD68/ED1 (1:100; Santa Cruz Biotechnology) overnight at $4^{\circ} \mathrm{C}$, then washed with PBS and incubated with 1:200 TRITC or FITCconjugated goat anti-rabbit/mouse IgG secondary antibodies for $1 \mathrm{~h}$ at $37^{\circ} \mathrm{C}$ (Invitrogen, Carlsbad, Calif., USA). The sections were finally coverslipped with antifade Gel/Mount aqueous mounting media (SouthernBiotech, Birmingham, Ala., USA). All control sections were incubated in PBS without primary antibodies. Photographs of GAP-43 immunoreactive cells were counted, and immunoreactive areas of MPO, CD45 and CD-68 were analyzed with the NIH image software.

\section{Western Blotting}

The rats were killed by decapitation at $24 \mathrm{~h}, 1$ week and 6 weeks after SCI ( $\mathrm{n}=3$ per group), and one $10-\mathrm{mm}$ spinal cord segment containing the injury epicenter was prepared for Western blot. Total proteins were extracted from intact spinal cord with $2 \mathrm{mM}$ PMSF in $1 \mathrm{ml}$ ice-cold RIPA buffer, and then added to EDTA-free 

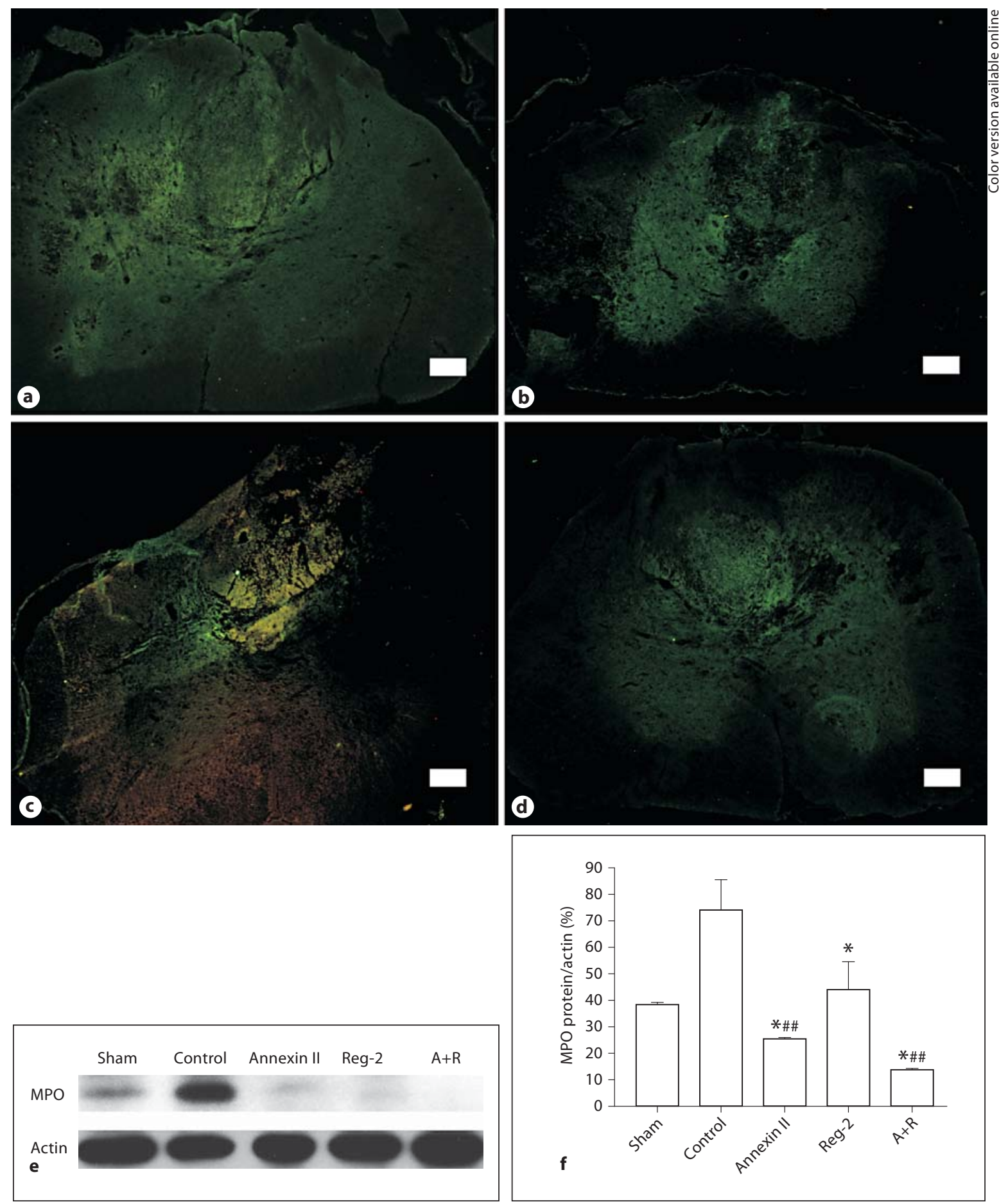

Fig. 1. Annexin II and Reg-2 treatment can reduce neutrophil infiltration in injured spinal cord at $24 \mathrm{~h}$ after contusion. a-d FITCconjugated MPO immunofluorescent staining, transverse section through injury epicenter. Bar $=200 \mu \mathrm{m}$. a Vehicle control group. b Annexin II-treated group. c Reg-2-treated group. d A+Rtreated group. e Level of MPO expression declined remarkably after annexin II and Reg-2 application compared with the vehicle control evaluated by Western blotting analysis at $24 \mathrm{~h}$ after injury. $\mathbf{f}$ Level of MPO expression at $24 \mathrm{~h}$ following SCI, densitometric analysis of Western blot bands. Mean ratio was recorded as densitometric ratio vs. $\beta$-actin. Column graph depicts the mean densitometric value of MPO: $\beta$-actin. ${ }^{*} \mathrm{p}<0.01$ vs. vehicle control; ${ }^{\#} \mathrm{p}<0.01$ vs. Reg-2-treated group. 
protease inhibitor cocktail. Protein concentrations were determined using the Bradford protein assay. SDS-PAGE was performed on $15 \%$ polyacrylamide slab gel, and separated proteins were then electrophoretically transferred to PVDF membrane at $70 \mathrm{~V}$ for $1.5 \mathrm{~h}$ at $4^{\circ} \mathrm{C}$ in a Bio-Rad TransBlot apparatus. After blocking nonspecific binding sites with bovine serum albumin, each membrane was incubated for $12 \mathrm{~h}$ at room temperature with primary rabbit polyclonal anti-MPO (1:200) for $24 \mathrm{~h}$, anti-GFAP $(1: 500)$ for 6 weeks, anti-TNF- $\alpha$ (1:2,000), anti-caspase 3 (1:500), or mouse monoclonal anti-GAP43 (1:200; Santa Cruz Biotechnology) for 1 week and 6 weeks. The membrane was washed three times for $5 \mathrm{~min}$ with TBST at room temperature, incubated with a secondary horseradish peroxidase (HRP)-conjugated goat antirabbit (1:5,000; Santa Cruz Biotechnology) or HRP-conjugated goat anti-mouse secondary antibody (1:5,000; Santa Cruz Biotechnology) for $1 \mathrm{~h}$ and then washed with TBST again. The Western blot was visualized using the ECL Plus detection system as described in the technical manual provided by Amersham Pharmacia Biotech, Inc., followed by imaging and quantification of protein bands using Bio-Rad Quantity One 1-D software. To normalize protein bands to a gel-loading control, membranes were washed in TBST and reprobed with rabbit anti- $\beta$-actin $(1: 5,000$; AbCam, Mass., USA) followed by incubation with peroxidaseconjugated goat anti-rabbit (1:5,000; Santa Cruz Biotechnology) and ECL detection. For the negative control, the primary antibody was omitted.

\section{Statistical Analysis}

Data are presented as mean $\pm \mathrm{SD}$. One-way analysis of variance with post-hoc Tukey $t$ tests was used to determine statistical significance. A p value of $<0.05$ was considered statistically significant. All statistical analyses and graphs were performed or generated with GraphPad Prism v4.0 (GraphPad Prism Software, Inc., San Diego, Calif., USA).

\section{Results}

\section{Annexin II and Reg-2 Treatment Inhibited}

\section{Inflammatory Reaction after SCI}

MPO was employed as a marker for neutrophil infiltration, CD45 for extravasated leukocytes and CD68 for activation of resident microglia and extravasated macrophages. The results showed that MPO-positive-labeled cells greatly increased in the vehicle-treated group over most of the cross sections of the spinal cord at the injury epicenter $24 \mathrm{~h}$ after transection (fig. 1a), while large numbers of CD45 and CD68 positive-labeled cells aggregated in this area at 7 days and 42 days after injury (fig. 2, 3a, e). The infusion of annexin II and Reg-2 protein resulted in a significant decrease in MPO activity and neutrophil infiltration at $24 \mathrm{~h}(\mathrm{p}<0.01$, fig. 1f) following SCI, as well as a decline of leukocyte infiltration and macrophage extravasation at 7 days and 42 days after injury $(\mathrm{p}<0.01$, fig. 2,3). The annexin II- and A+R-treated groups gener- ally had better effects than Reg-2-treated groups at each different time point ( $p<0.05$, fig. $4 a, b, e, f)$. Regression analysis showed that the inflammation at 7 or 42 days after injury correlated with white matter loss $(p<0.0001$, fig. $4 c, d, g, h)$.

\section{Annexin II and Reg-2 Treatment Reduced White}

Matter Loss and Demyelination, and Prevented Tissue Damage, Cavity Formation, Axon Degeneration and

Reactive Gliosis following SCI

The percentage of white matter sparing area and spared axons in the injury epicenter as well as the percentage of lesion volume (cystic cavity volume) at 1 and 6 weeks after injury was investigated. The injury epicenter with the least white matter sparing was determined in transverse sections by the minimum area of myelination shown with LFB staining along the spinal cord axis. Measurements of percent lesion volume were taken from HE staining transverse sections spanning the entire lesion.

In the vehicle control, 1 week following SCI, only $36 \%$ of the ventral and dorsolateral white matter remained compared to sham-operated rats (fig. 5a). Annexin IItreated rats could keep myelination area up to $51 \%$ of the sham group, implying much more spared white matter remained compared with vehicle control ( $\mathrm{p}<0.01$, fig. $5 \mathrm{a}$ ). The Reg-2- and A+R-treated groups could further increase the white matter sparing area to 61 and $62 \%$ of the sham group, which is significantly different compared with annexin II-treated group ( $p<0.05$, fig. 5a).

At 6 weeks following SCI, with the formation of cystic cavity, the white matter sparing area in each group decreased further (fig. 5b, c). Rats in the three drug-infused groups were found to have much more visible spared white matter, and this was significant compared with vehicle control ( $\mathrm{p}<0.01$, fig. 5b). At 6 weeks following injury, the Reg-2- and A+R-treated groups still had more spared white matter than the annexin II-infused group $(\mathrm{p}<0.01$, fig. $5 \mathrm{~b})$, while there was no significant difference between these two groups.

Numerous black-color degenerating axons as well as loose axons were demonstrated in the vehicle group with Eager's silver staining (fig. 6, 7e), while within the Reg-2and annexin II-treated groups, larger areas of normalstained axons were observed either at 7 days or 42 days following SCI (fig. 6, 7f-h). Regression analysis showed that white matter sparing area at 7 and 42 days after injury all correlated with BBB scores ( $p<0.05$, fig. $5 d$, e).

Six weeks following SCI, large cystic cavity appeared in the central core region of the spinal cord in the saline vehicle group; transverse section showed that most of the 


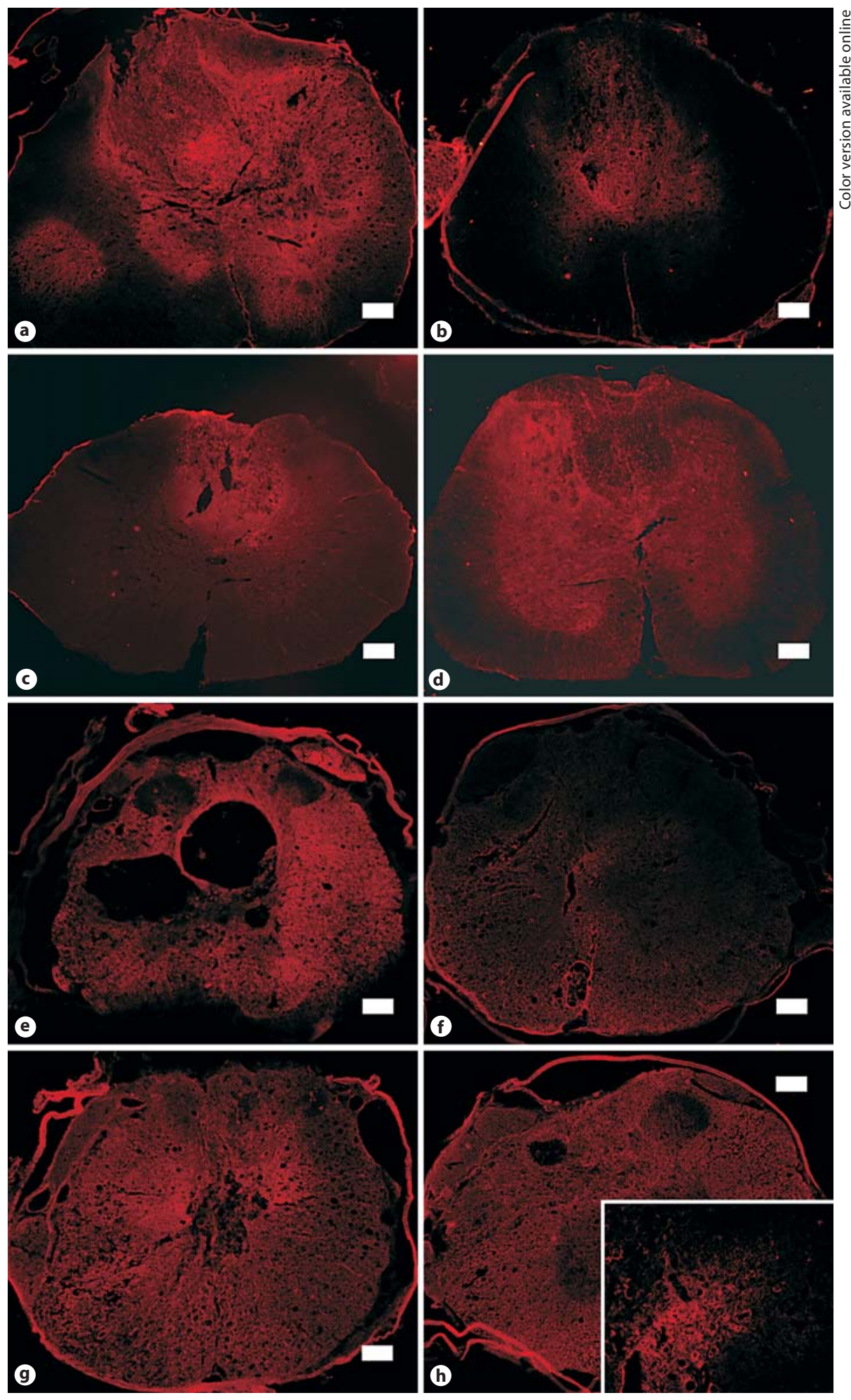

Fig. 2. Annexin II and Reg-2 treatment can reduce extravasated macrophages in injured spinal cord both at 7 and 42 days after contusion. TRITC-conjugated CD45 immunofluorescent staining, transverse section through injury epicenter. a-d Images taken at 7 days after injury. a Vehicle control group. b Annexin
II-treated group. c Reg-2-treated group. d A+R-treated group. e-h Images taken at 42 days after injury. e Vehicle control group. f Annexin II-treated group. g Reg-2-treated group. $\mathbf{h}$ A+R-treated group. Bar $=200 \mu \mathrm{m}$. 

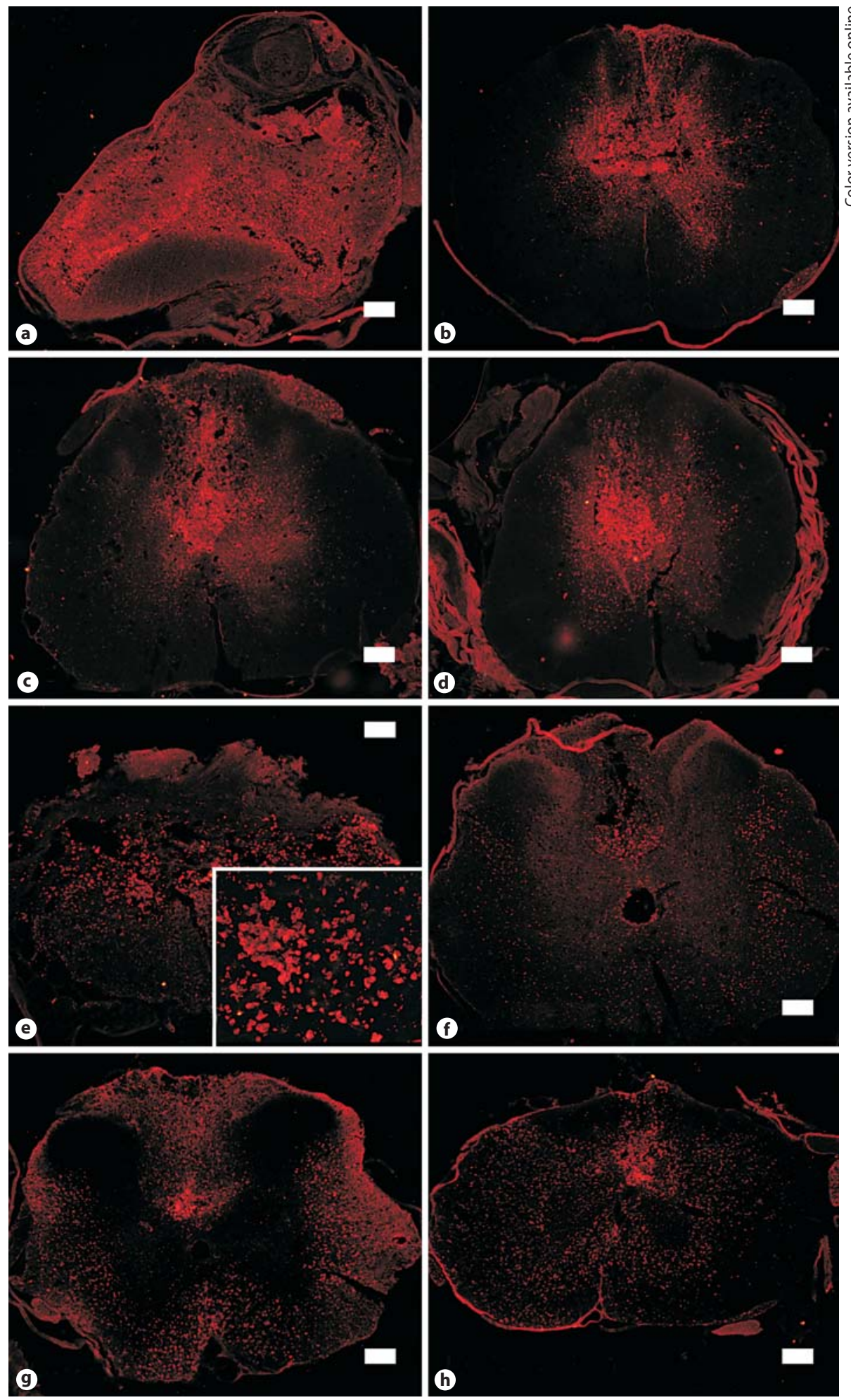

Fig. 3. Annexin II and Reg-2 treatment can reduce extravasated macrophages in injured spinal cord both at 7 and 42 days after contusion. TRITC-conjugated CD68 immunofluorescent staining, transverse section through injury epicenter. a-d Images taken at 7 days after injury. a Vehicle control group. b Annexin
II-treated group. c Reg-2-treated group. d A+R-treated group. e-h Images taken at 42 days after injury. e Vehicle control group. f Annexin II-treated group. g Reg-2-treated group. $\mathbf{h}$ A+R-treated group. Bar $=200 \mu \mathrm{m}$. 

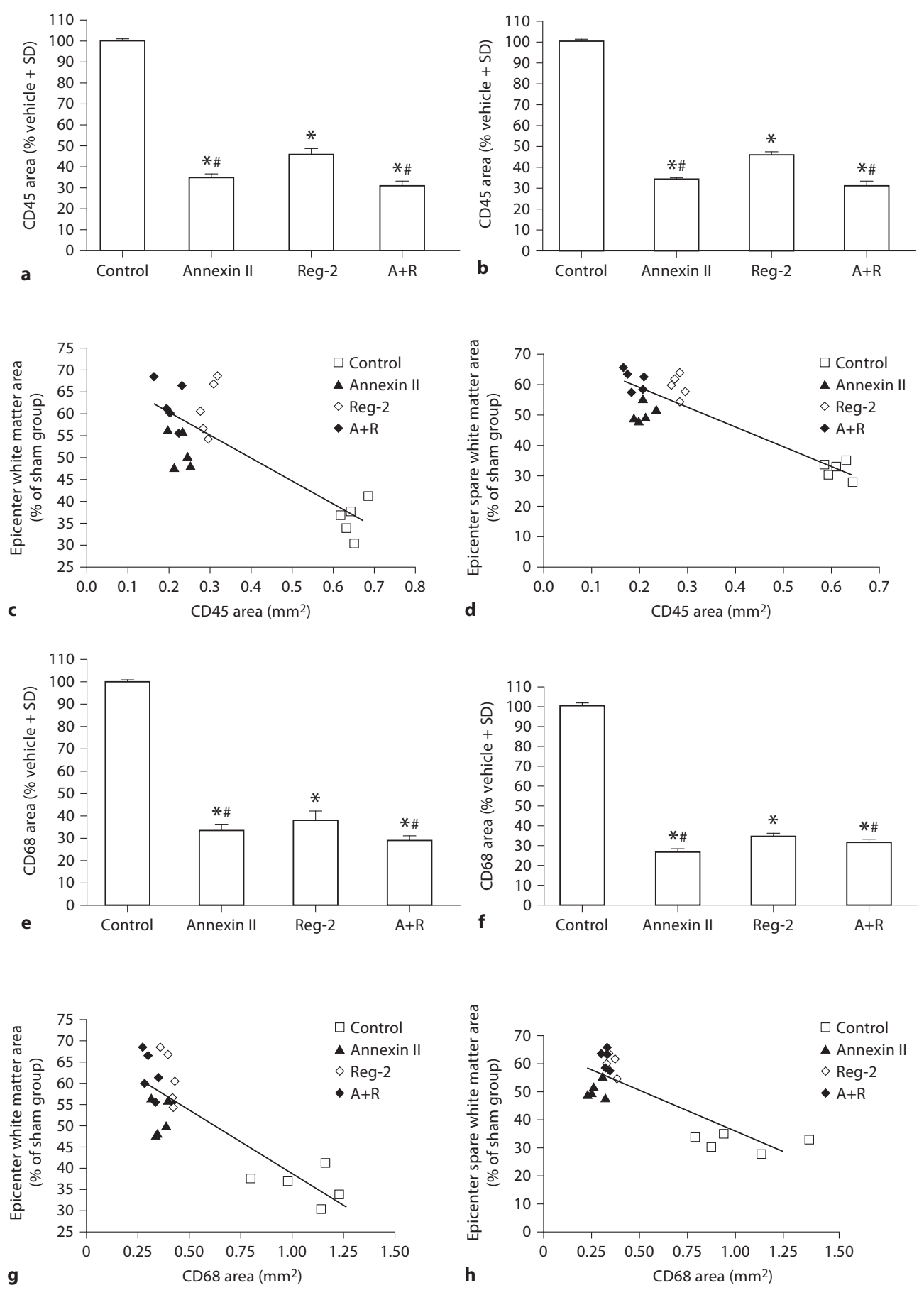

Fig. 4. Annexin II and Reg-2 treatment inhibited inflammatory reaction after SCI. a, b Area immunostained for CD45+ cells (\% of vehicle control) in each group 7 days (a) and 42 days (b) following SCI. ${ }^{*} \mathrm{p}<0.01$ vs. vehicle control; ${ }^{*} \mathrm{p}<0.05$ vs. Reg-2-treated group. c, d At both 7 days (c) and 42 days (d) following SCI, the area of CD45 immunostaining correlated well with spared white matter at injury epicenter $\left(7\right.$ days $\mathrm{r}^{2}=0.6028, \mathrm{p}<0.0001,42$ days $\left.\mathrm{r}^{2}=0.7790, \mathrm{p}<0.0001\right)$. e, f Area immunostained for CD68+ cells (\% of vehicle control) in each group 7 days (e) and 42 days (f) following SCI. ${ }^{*} \mathrm{p}<0.01$ vs. vehicle control; ${ }^{\#} \mathrm{p}<0.05$ vs. Reg-2treated group. $\mathbf{g}, \mathbf{h}$ At both 7 days (g) and 42 days (h) following SCI, the area of CD68 immunostaining correlated well with spared white matter at the epicenter $\left(7\right.$ days $\mathrm{r}^{2}=0.7121, \mathrm{p}<0.0001$, 42 days $\left.\mathrm{r}^{2}=0.6980, \mathrm{p}<0.0001\right)$. 


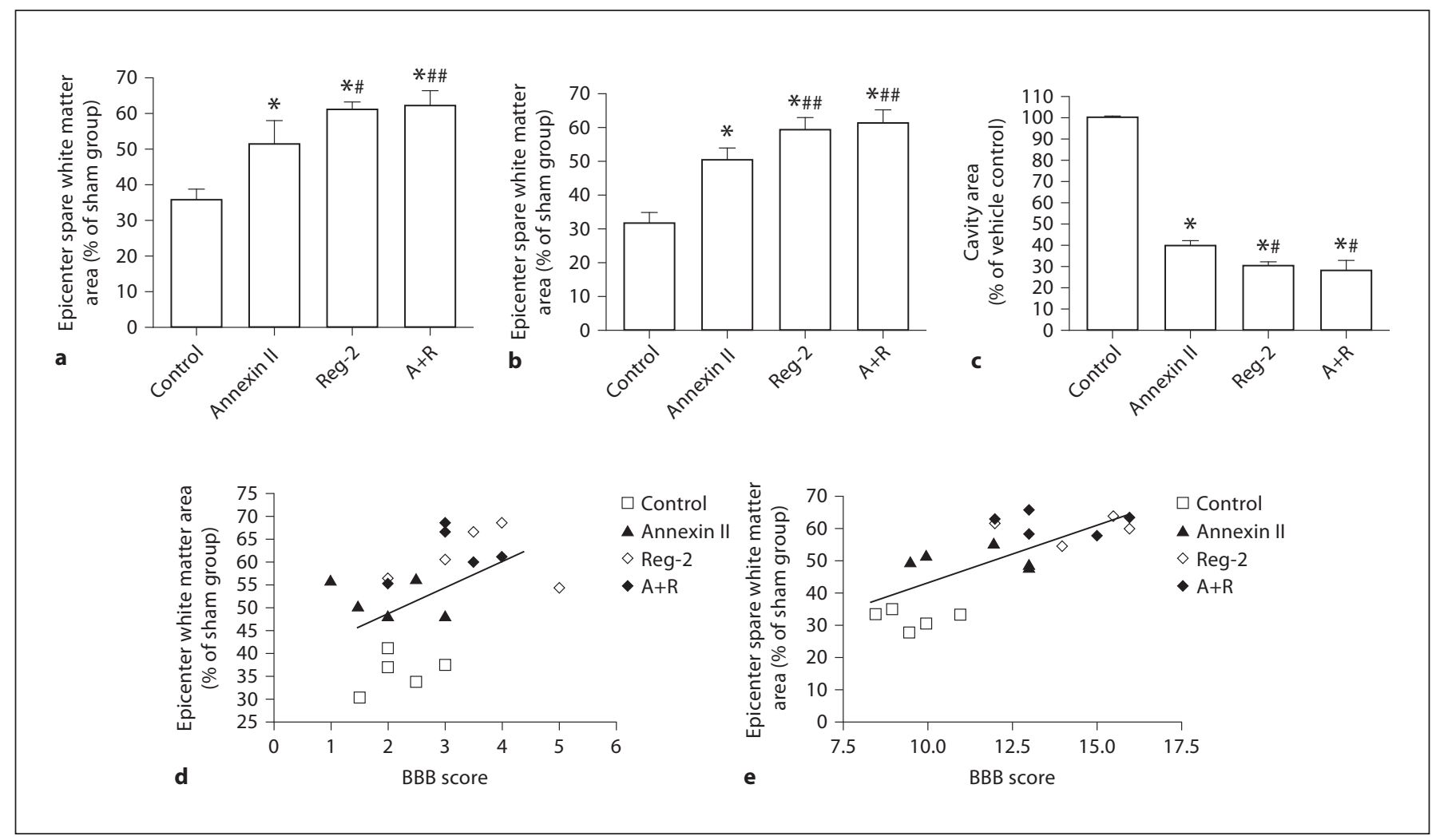

Fig. 5. Annexin II and Reg-2 treatment attenuated demyelination and reduced tissue damage volume at 7 and 42 days following SCI. White matter sparing area (\% of sham) at injury epicenter in each group 7 days (a) and 42 days (b) following SCI. c Area of cystic cavity at injury epicenter in each group 42 days following SCI. ${ }^{*} \mathrm{p}<0.01$ vs. vehicle control. ${ }^{\#} \mathrm{p}<0.05$ vs. annexin II-treated group; ${ }^{\# \#} \mathrm{p}<0.01$ vs. annexin II-treated group. d Seven days following SCI, the spared white matter at the epicenter correlated well with locomotor performance measured by BBB score $\left(\mathrm{r}^{2}=\right.$ 0.2135 , $\mathrm{p}<0.05)$. e Forty-two days following SCI, the spared white matter at the epicenter correlated well with locomotor performance as measured by BBB score $\left(\mathrm{r}^{2}=0.5491, \mathrm{p}=0.0002\right)$. spinal cord parenchyma was destroyed and only a rim of tissue remained (fig. 8e). In the annexin II-, Reg-2- and A+R-treated groups, the lesion volume decreased to 39, 30 and $28 \%$ of vehicle control, respectively (fig. $5 c, 8$ ), and all these drug-infused rats had much smaller cavity area $(\mathrm{p}<0.01$, fig. $5 \mathrm{c})$. Significant statistical differences were shown among the Reg- 2 protein, the A+R-treated, and the annexin II-treated groups ( $\mathrm{p}<0.05$, fig. $5 \mathrm{c}$ ).

NF-IR-stained axons appeared in the area of cavity in each group (fig. 9). In vehicle control, the unchained NFIR axons mixed with glial tissues surrounded the cavity, but rarely passed through the injury epicenter (fig. 9a). Nevertheless, numerous NF-IR axon profiles were found in drug-infused groups adjacent to the lesion epicenter and penetrated heavily the spared white matter area (fig. 9b-d). Meanwhile, to assess whether our treatments could inhibit SCI-induced reactive gliosis, we examined expression of GFAP, a marker for astrocytes, in the rat spinal cord at 6 weeks after SCI. Western blot analysis revealed that SCI induced an increase in GFAP expression while annexin II and combined drug delivery resulted in a marked decrease in GFAP expression ( $p<0.01$, fig. 10f). No inhibitory effect on astrogliosis was confirmed in the Reg-2-treated group ( $p>0.05$, fig. 10f).

\section{Annexin II and Reg-2 Treatment Increased Axonal Sparing of Propriospinal and Supraspinal Origins}

Both Reg-2 and annexin II treatment resulted in a significant increase in the mean number of FG-labeled propriospinal neurons located at both $\mathrm{T}_{5}$ and $\mathrm{C}_{6}$ spinal levels (fig. 11). However, no statistically significant difference was found in the number of FG-labeled cells among the three treated groups at either cord level ( $p>0.05$, fig. 12a). 
Fig. 6. Annexin II and Reg-2 treatment can reduce white matter loss, protect myelination and prevent axon degeneration in transected spinal cord at 7 days after injury. a-d LFB staining. e-g Eager's silver staining, transverse section. Bar $=200$ $\mu \mathrm{m}$. a Vehicle control group. b Annexin II-treated group. c Reg-2-treated group. d A+R-treated group. e Vehicle control group. f Annexin II-treated group. g Reg2-treated group. $\mathbf{h} \mathrm{A}+\mathrm{R}$-treated group.

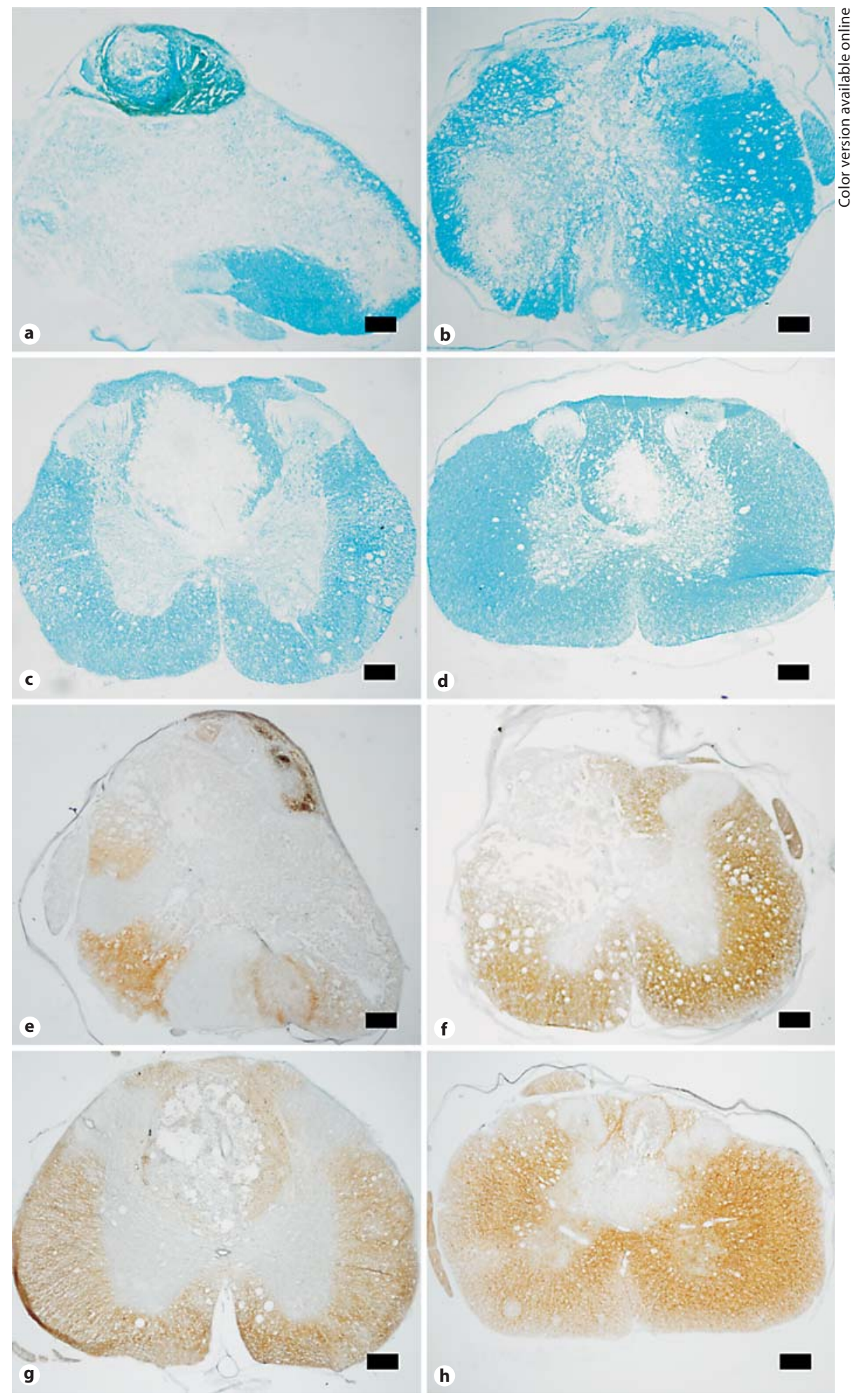


Fig. 7. Annexin II and Reg-2 treatment can reduce white matter loss, protect myelination and prevent axon degeneration in transected spinal cord at 42 days after injury. a-d LFB staining. e-g Eager's silver staining, transverse section. Bar $=200$ $\mu \mathrm{m}$. a Vehicle control group. b Annexin II-treated group. c Reg-2-treated group. d A+R-treated group. e Vehicle control group. f Annexin II-treated group. g Reg2-treated group. $\mathbf{h} \mathrm{A}+\mathrm{R}$-treated group.

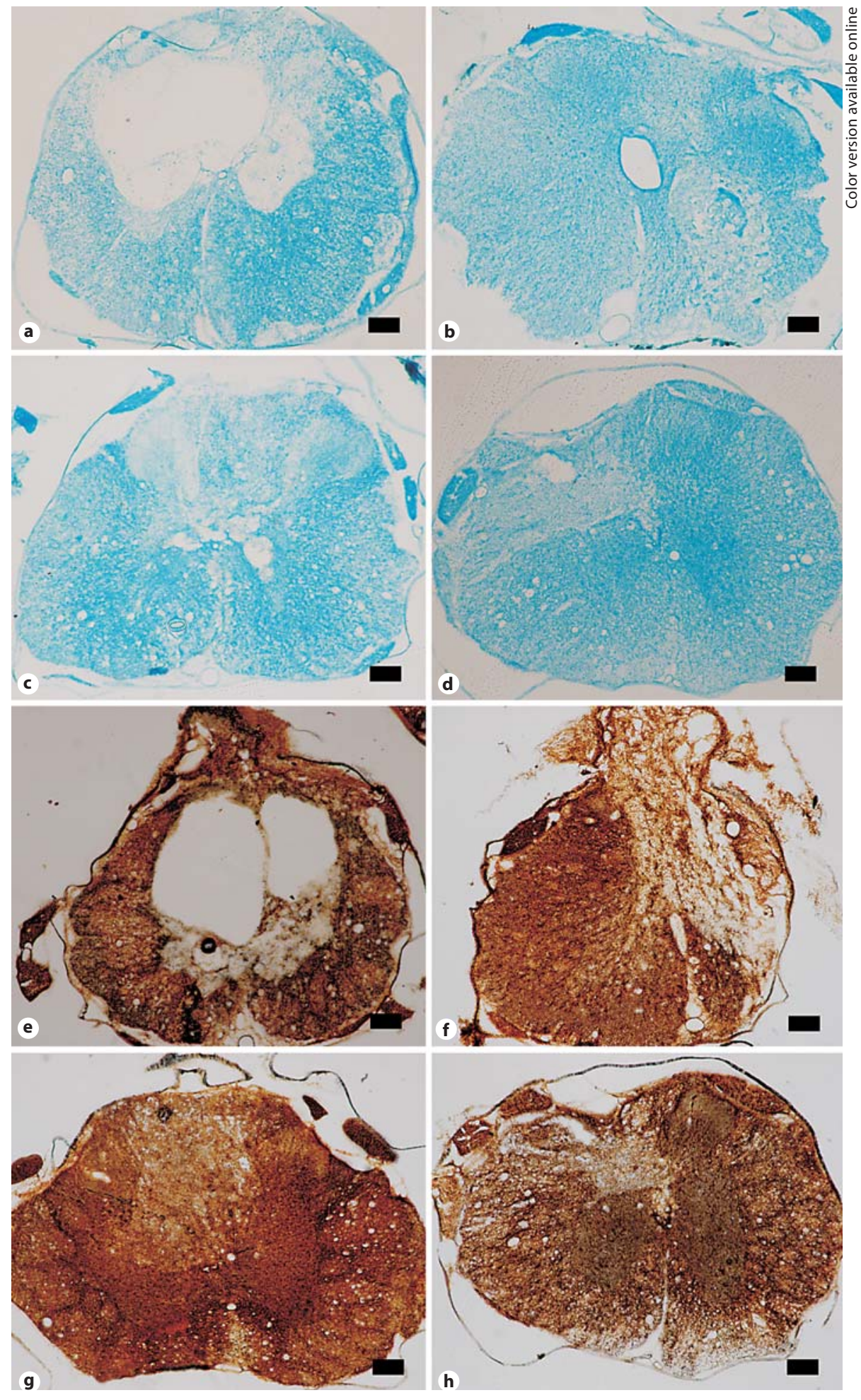



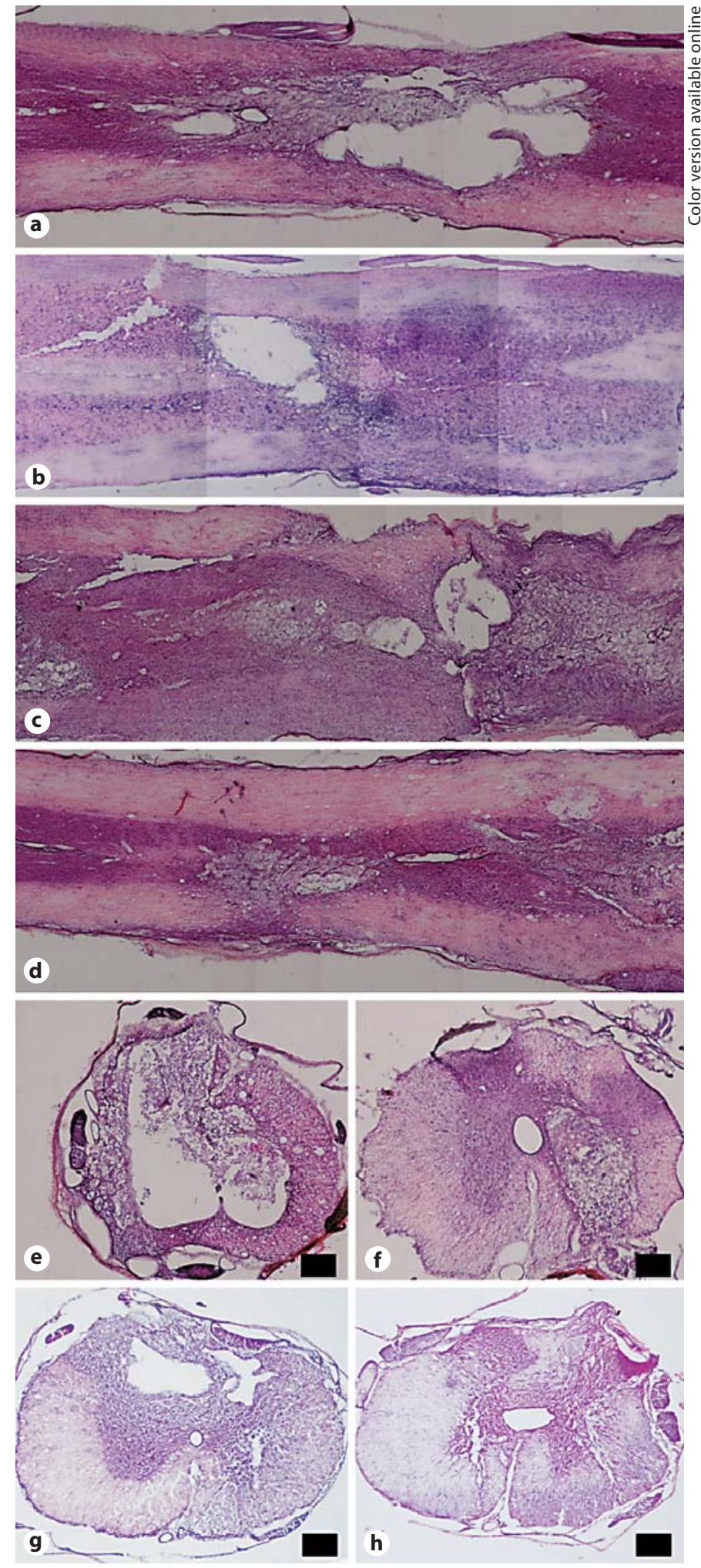

FG-labeled neurons in selected supraspinal nuclei were also counted to determine whether the annexin II and Reg- 2 could induce a reduction in lesion volume and an increase in axons of spared neurons in these areas (fig. 12b, 13, 14). Single and combined treatment with annexin II and Reg-2 led to a statistically significant increase in FG-labeled neurons in SPT, DT, Pnc, Ctx-HL and RN ( $p<0.01$, fig. 12b, 13, 14). Significant differences were found between the Reg- 2 protein, A+R-treated and annexin II-treated groups in Ctx-HL and RN but not in SPT, DT and Pnc ( $<<0.05$, fig. 12b).

\section{Annexin II and Reg-2 Treatment Promoted Functional Recovery after SCI}

The scores of behavioral assessments for 6 weeks after SCI were measured (fig. 15). Sham-operated animals showed consistent scores, and there was no tendency of improved performance with experience. All injury rats developed obvious bilateral hind-limb paralysis immediately following injury. At the first week after injury, the Reg- 2 protein and the A+R-treated groups began to display better behavioral scores compared with vehicle control group ( $\mathrm{p}<0.05$, fig. 15), while there was no significant difference detected between the annexin-treated group and vehicle control until the fifth week after SCI (fig. 15). Six weeks after injury, all injured rats showed behavioral recovery, and all the drug-infused groups displayed remarkable functional improvement versus control ( $\mathrm{p}<0.05$, fig. 15); moreover, the Reg-2 protein and the A+R-treated groups earned better scores compared with the annexin II-treated group ( $\mathrm{p}<0.05$, fig. 15).

Fig. 8. Annexin II and Reg-2 treatment can reduce the cystic cavity area induced by SCI. HE staining. a-d Horizontal section through injury epicenter. e-g Transverse section through injury epicenter. Bar $=200 \mu \mathrm{m}$. a Vehicle control group. b Annexin IItreated group. c Reg-2-treated group. $\mathbf{d} \mathrm{A}+\mathrm{R}$-treated group. e Vehicle control group. f Annexin II-treated group. g Reg-2-treated group. $\mathbf{h}$ A+R-treated group. 


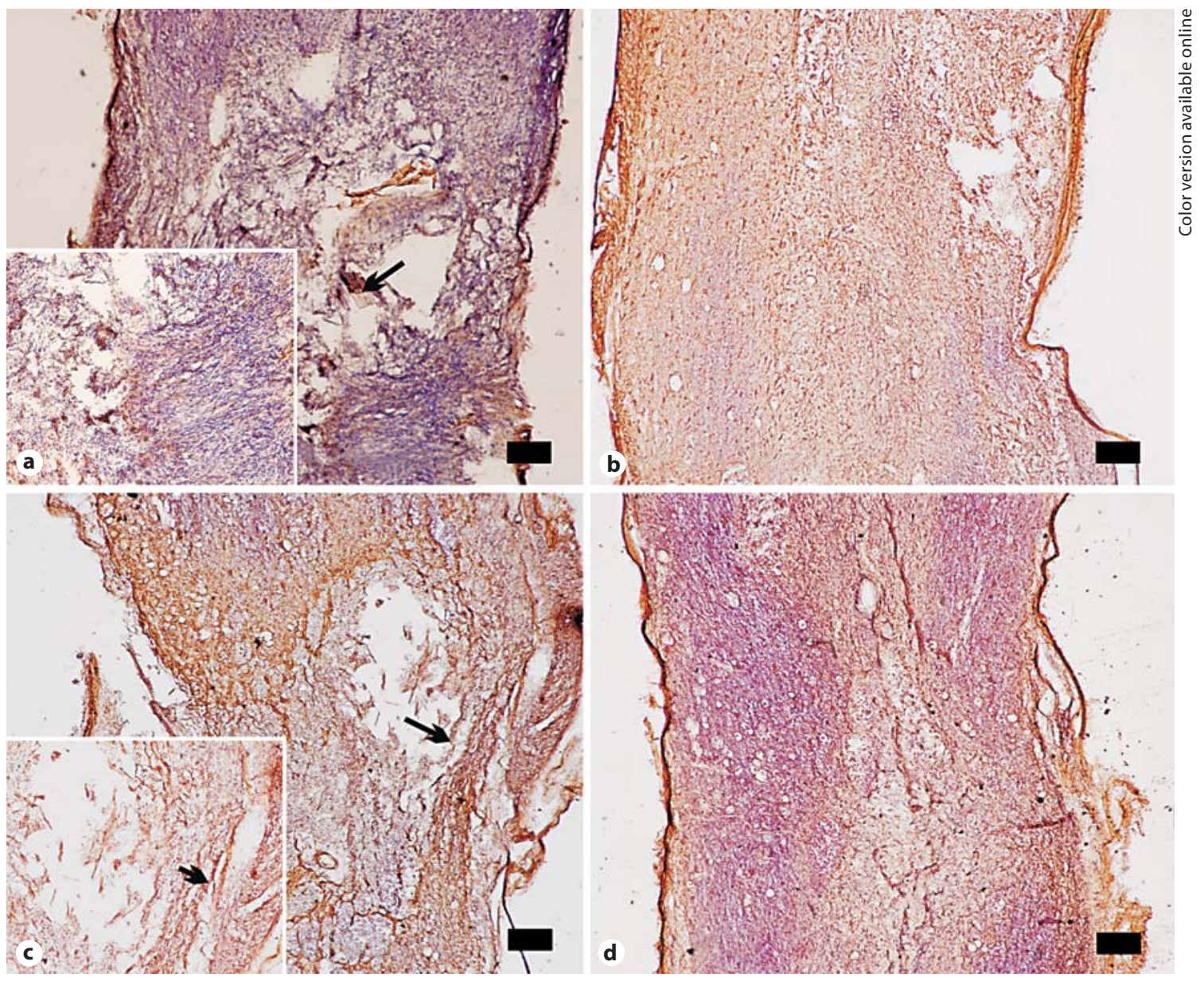

Fig. 9. Spared white matter of annexin II- and Reg-2-treated groups all contained numerous axons. Horizontal section through injury epicenter. NF-IR counterstained with hematoxylin. Bar $=200 \mu \mathrm{m}$. a Vehicle group (amplificatory image was inserted). Arrow showed the unchained NF-IR axons mixed with glial tissues surrounded the cavity, but rarely pass through the injury epicenter. b Annexin II-treated group. c Reg-2-treated group (amplificatory image was inserted). Arrows showed axon profiles found adjacent to the lesion epicenter and penetrated the spared white matter area. $\mathbf{d} \mathrm{A}+\mathrm{R}$-treated group.

Annexin II and Reg-2 Treatment Inhibited Apoptosis and Reduced Neuron Loss in Injured Spinal Cord

There was remarkable neuron loss in the anterior horn of the spinal cord following SCI (fig. 16a, b, 17). Compared with vehicle control, Reg-2 and annexin treatment significantly reduced the neuron loss induced by injury at both 7 days and 42 days following SCI ( $\mathrm{p}<0.01$, fig. 16a, b). Significant differences were found between the A+Rand annexin II-treated groups at 7 days following SCI $(\mathrm{p}<0.05)$, but not at 42 days ( $\mathrm{p}>0.05$, fig. 16a, b).

The caspase-3 IR neural cells revealed by immunostaining were evidently reduced in the Reg- 2 protein and annexin-treated groups from 1 to 6 weeks following SCI
( $\mathrm{p}<0.01$, fig. 18e, f). Moreover, Western blot analysis revealed that SCI induced a significant increase in active caspase-3 expression, which was significantly reversed by the treatments, especially in the Reg-2- and A+R-treated groups and in the early stage following SCI (fig. 19). The $\mathrm{A}+\mathrm{R}$ group has much less caspase-3 IR neural cells than single treatment groups at 7 days after injury (fig. 18e), and at 42 days after SCI, the combined treatment group has less caspase-3 IR neural cells compared with annexin II-treated groups ( $p<0.01$, fig. 18f). There was a significant difference between the annexin II- and Reg-2-treated groups at 7 days $(p<0.01)$ but not at 42 days after SCI $(p>0.05$, fig. 18e, f). 

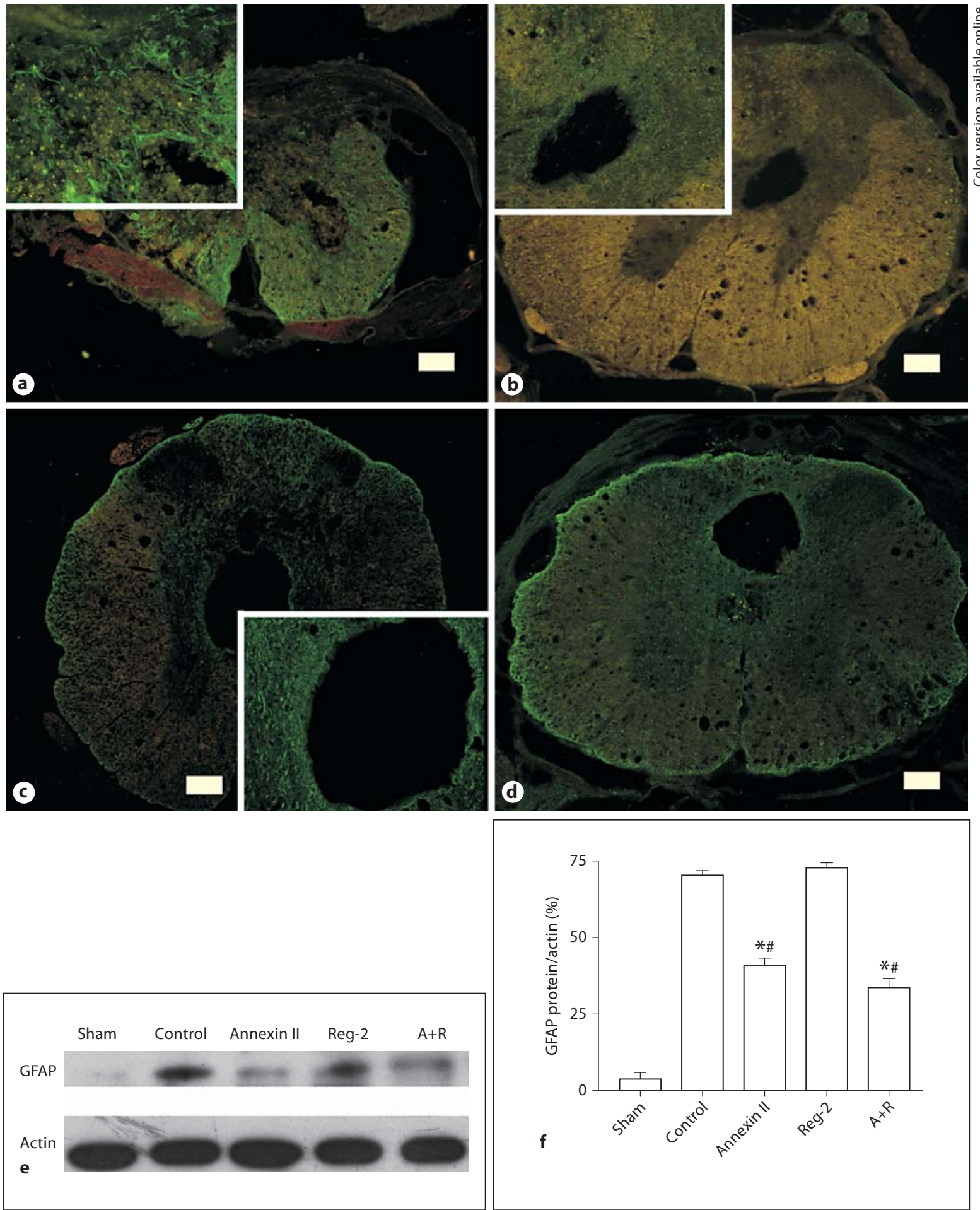

Fig. 10. Annexin II and Reg-2 treatment can reduce reactive gliosis in injured spinal cord at 6 weeks after contusion. a-d FITCconjugated GFAP immunofluorescent staining, transverse section. Bar $=200 \mu \mathrm{m}$. Amplificatory images were inserted within a (vehicle control group), b (annexin II-treated group) and c (Reg2-treated group). d A+R-treated group. e Analysis of Western blots for GFAP expression profile. The level of GFAP expression declined remarkably after annexin II and $A+R$ application as compared with the vehicle control at 6 weeks after injury. $\mathbf{f}$ The level of GFAP expression at 6 weeks following SCI, densitometric analysis of Western blotting bands. Column graph depicts the mean densitometric value of GFAP: $\beta$-actin. ${ }^{*} \mathrm{p}<0.01$ vs. vehicle control; ${ }^{\#} \mathrm{p}<0.01$ vs. Reg-2-treated group. 

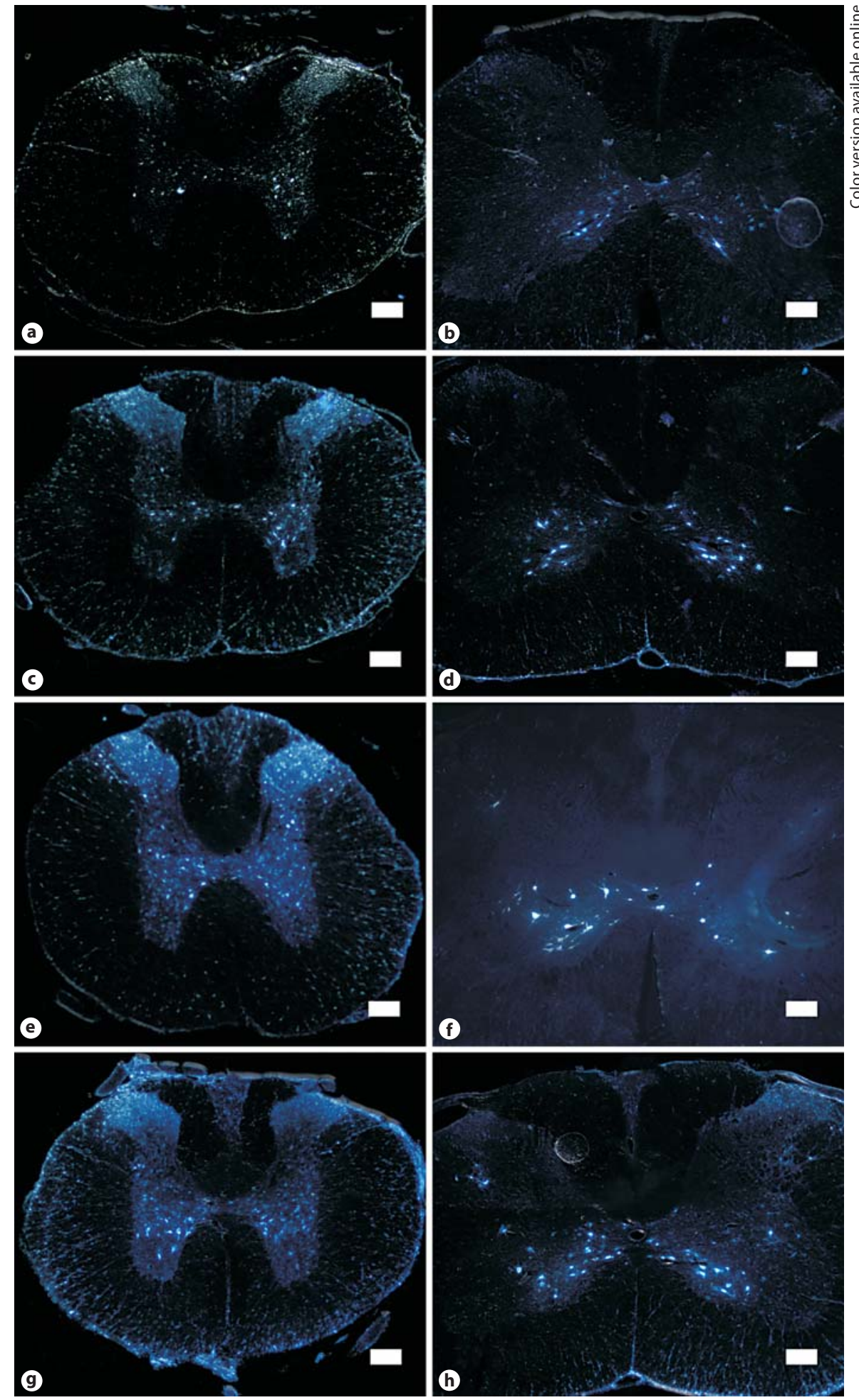

Fig. 11. Annexin II and Reg-2 resulted in a significant increase in the number of FG-labeled neurons located at both $\mathrm{T}_{5}$ and $\mathrm{C}_{6}$ spinal levels vs. vehicle group $(\mathbf{a}, \mathbf{b})$. The FG was injected into the lumbar enlargement, approximately $12 \mathrm{~mm}$ caudal to the injury. In all cases, FG-labeled neurons were predominantly distributed within lamina VII and the medial portion of lamina VIII that form propriospinal projections. An increase in the number of FGlabeled neurons was found after treatment with annexin II (c, d), Reg-2 (e, f), and A+R treatments $(\mathbf{g}, \mathbf{h})$ compared with the vehicle

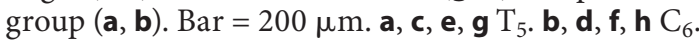




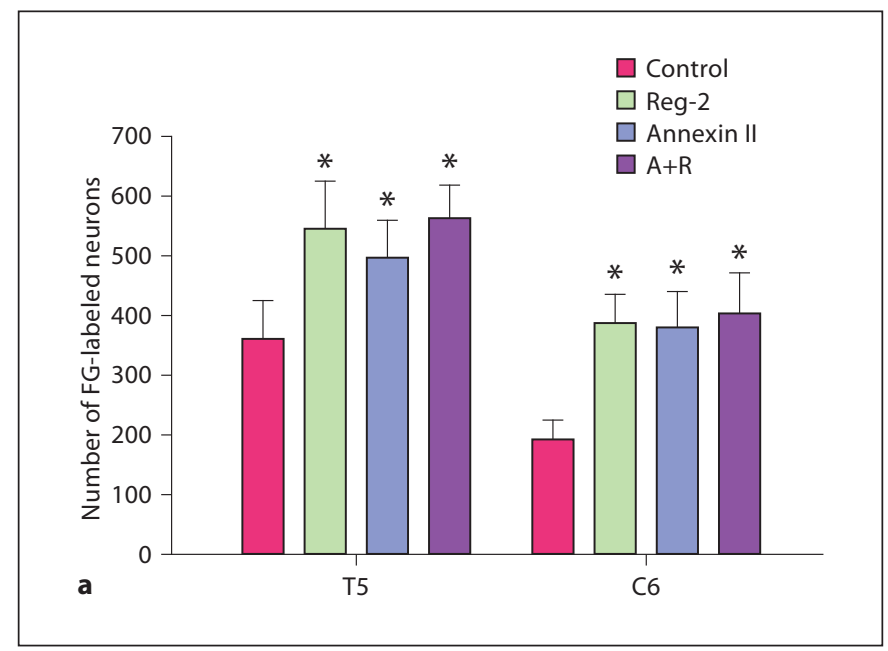

Fig. 12. Effect of annexin II and Reg-2 treatment on the amount of propriospinal and supraspinal axons (4 rats/group; mean \pm $\mathrm{SD})$. a Spared propriospinal axons as measured by counting the number of FG-labeled neurons in the $\mathrm{T}_{5}$ and $\mathrm{C}_{6}$ spinal segments.

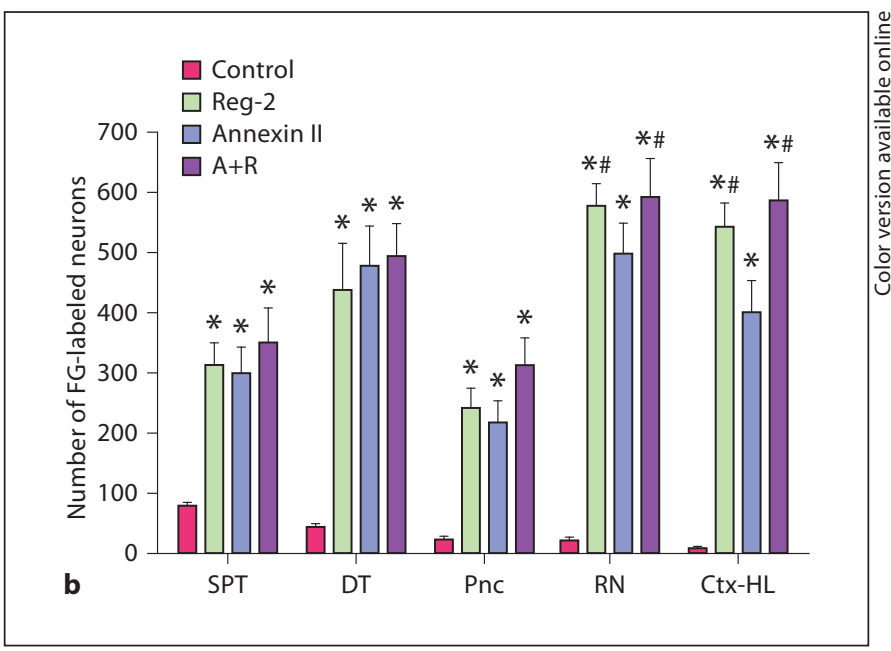

* $\mathrm{p}<0.05$ vs. vehicle control. b Spared supraspinal axons as measured by counting the number of FG-labeled neurons in selective brainstem nuclei at 6 weeks after SCI. ${ }^{*} \mathrm{p}<0.01$ vs. vehicle control; ${ }^{\#} \mathrm{p}<0.05$ vs. annexin II-treated group.
Annexin II and Reg-2 Treatment Promoted GAP-43 Expression and Inhibited TNF- $\alpha$ Expression

Extensive expression of TNF- $\alpha$ was found on neurons and other neural cells in the spinal cord following SCI in vehicle control, but the TNF- $\alpha$ IR neural cells were much less abundant in annexin II- and Reg-2-treated groups (fig. 20a-d). Western blot also demonstrated a remarkable decrease in TNF- $\alpha$ expression in each drug delivery group (fig. 21f). Such a decline in TNF- $\alpha$ IR neural cells detected in annexin II- and Reg-2-treated groups was found from 7 to 42 days after injury ( $p<0.01$, fig. 20, 21). There was significantly less TNF- $\alpha$ IR neural cells in the Reg-2 protein and combined treatment groups compared with the annexin II-treated group (fig. 20e, f).

Cell counting indicated that much more GAP-43-labeled cells were calculated among annexin II, Reg- 2 and combined treatment groups than vehicle control $(\mathrm{p}<$ 0.01 , fig. 22e, f). Immunolabeling showed that GAP-43positive staining was distributed in both cell bodies and neural fibers (fig. 22a-d). Western blot revealed that the expression of GAP-43 increased in the spinal cord of each injured animal (fig. 23). More GAP-43-labeled cells were found in the Reg- 2 protein and combined treatment groups compared with the annexin II-treated group ( $<<$ 0.01 , fig. 22,23 ), with statistically significant differences between these two groups at 7 days and 42 days following SCI $(p<0.05$, fig. 22e, f).

Effects of Annexin II and Reg-2 in in vivo Injury Models

\section{Discussion}

SCI is a major cause of disability [37]. Either direct mechanical injury (primary injury) or secondary pathophysiological mechanisms induced by the initial trauma could contribute to the functional decline following SCI [38-39]. The primary injury encompasses the focal destruction of neural tissue caused by direct mechanical trauma, which progresses to a wave of secondary injury to exacerbate SCI [37].

The neuroinflammatory reaction is an important factor contributing to the secondary injury and leads to demyelination, tissue damage and neuron loss at the following stage. The early recruitment of neutrophils into the surrounding parenchyma within $24 \mathrm{~h}$ after SCI, and leukocyte infiltration and macrophage extravasation at later stages cause exacerbation of injury; thus, targeting the neuroinflammatory reaction is an important remedial point to alleviate the secondary injury and improve the microenvironment to facilitate regeneration [40]. Our previous study has shown that the annexin II delivery inhibited MPO activity and suppressed SCI-induced neutrophil infiltration, which was believed as one important mechanism to cause subsequent tissue damage [20]. In later stages, annexin treatment also attenuated leukocyte infiltration and macrophage extravasation, which were the major contributors to demyelination in the injury site

Neurosignals 2011;19:16-43 


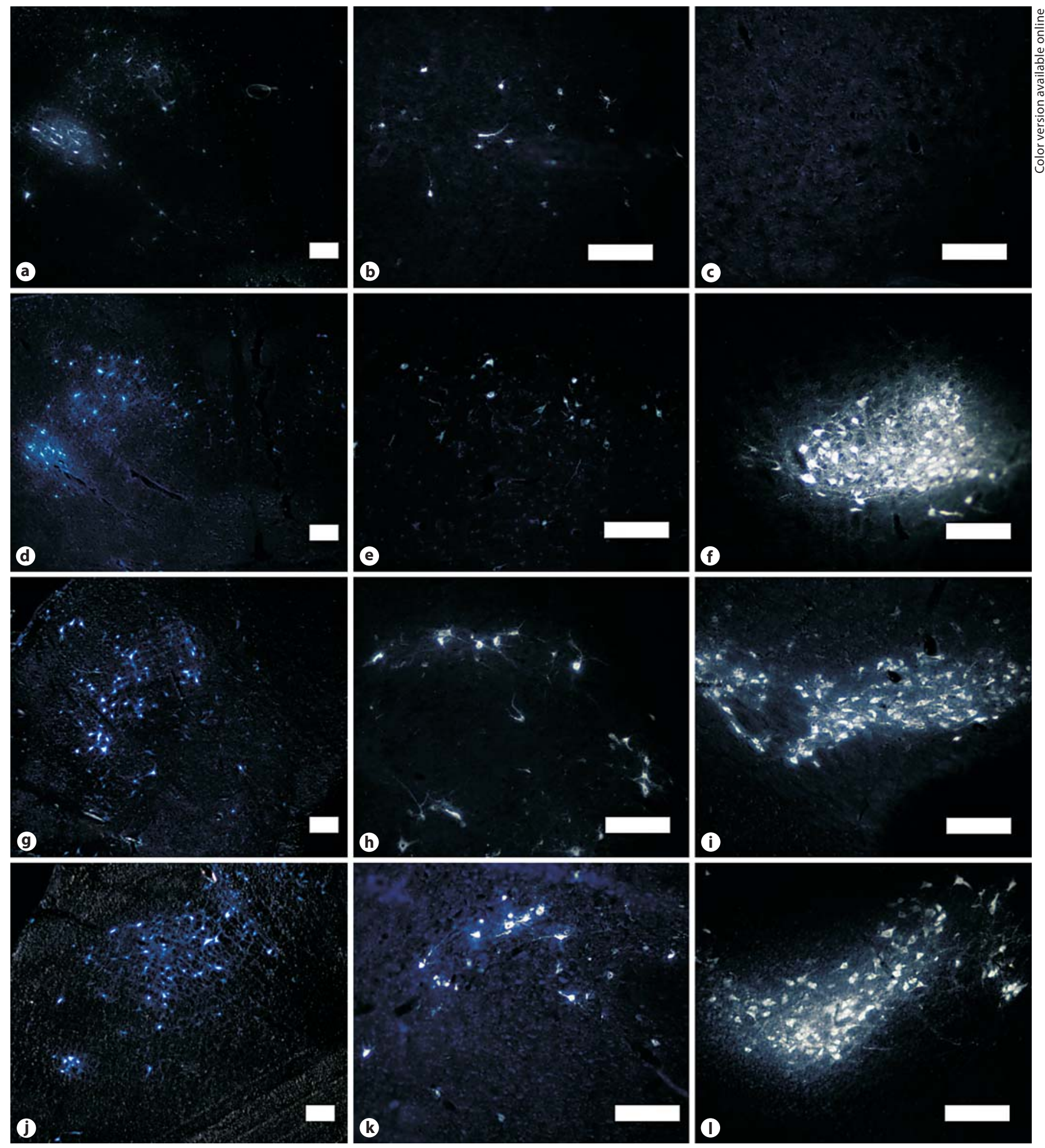

Fig. 13. Annexin II and Reg-2 treatment resulted in a significant increase in the number of FG-labeled neurons located in selective brainstem nuclei at the SPT, Pnc and the RN. a Vehicle group, SPT. b Vehicle group, Pnc. c Vehicle group, RN. d Annexin II-treated group, SPT. e Annexin II-treated group, Pnc. f Annexin II-treated group, RN. g Reg-2-treated group, SPT. h Reg-2-treated group, Pnc. i Reg-2-treated group, RN. j A+R-treated group, SPT. k A+Rtreated group, Pnc. I A+R-treated group, RN. Bar $=200 \mu \mathrm{m}$. 


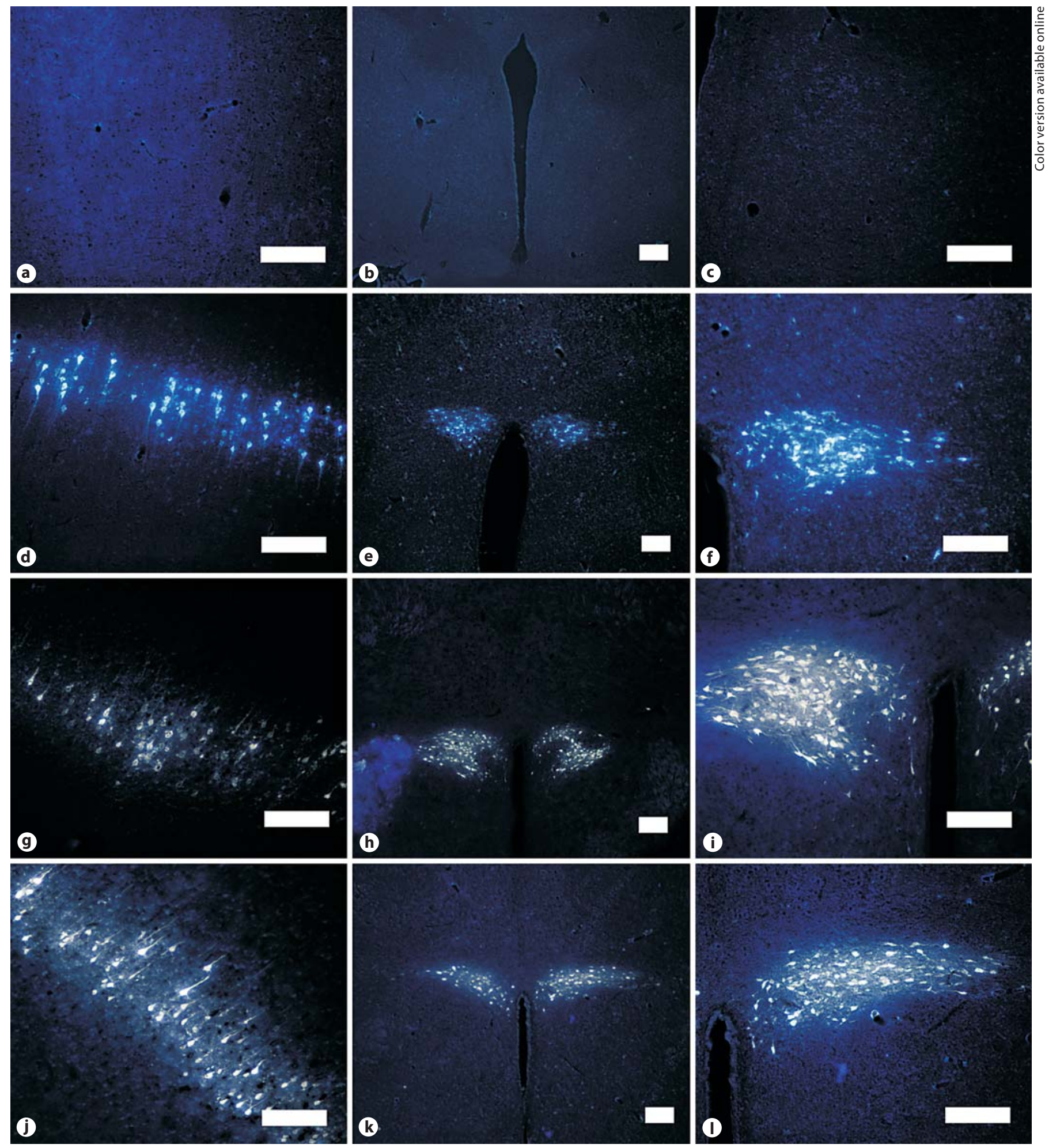

Fig. 14. Annexin II and Reg-2 treatment resulted in a significant increase in the number of FG-labeled neurons located in selective brainstem nuclei at the Ctx-HL and DT. a Vehicle group, Ctx-HL. b Vehicle group, DT. c Vehicle group, DT. d Annexin II-treated group, Ctx-HL. e Annexin II-treated group, DT. f Annexin II- treated group, DT. g Reg-2-treated group, Ctx-HL. h Reg-2-treated group, DT. i Reg-2-treated group, DT. j A+R-treated group, Ctx-HL. k A+R-treated group, DT. I A+R-treated group, DT. Bar $=200 \mu \mathrm{m}$. 
Fig. 15. The change in BBB score of each group indicates that annexin II and Reg-2 exert neuroprotective effects, inducing lasting improvements in locomotor performance following SCI. ${ }^{*} \mathrm{p}<0.05$ vs. vehicle control. ${ }^{* *} \mathrm{p}<0.01$ vs. vehicle control; ${ }^{\#} \mathrm{p}<0.05$ vs. annexin II-treated group.
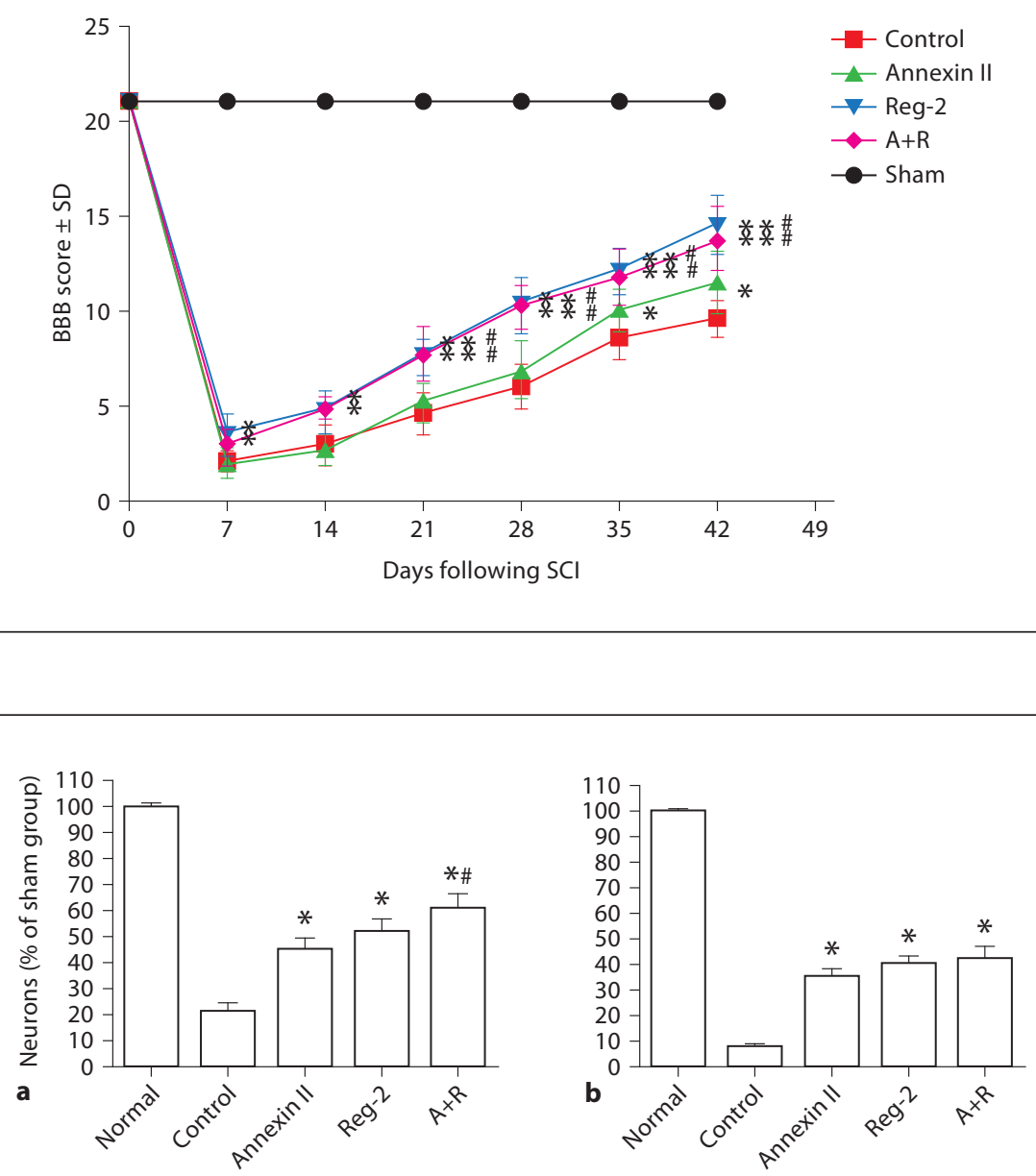
${ }^{*} \mathrm{p}<0.01$ vs. vehicle control; ${ }^{*} \mathrm{p}<0.05$ vs. annexin II-treated group.

[41-44]. Better anti-inflammatory effects at each time point was shown in the annexin II and combined treatment groups compared with the Reg-2-treated group; these results were consistent with previous studies on annexin I which can inhibit MPO activation and neutrophil as well as monocyte infiltration in SCI and other models of inflammation [20].

Meanwhile, the expression of one inflammatory cytokine, TNF- $\alpha$, which has long been considered as a cytokine that contributes to axon demyelination and a gliosis trigger, was detected [45]. The expression of TNF- $\alpha$ was reduced in the three treated groups, especially in the Reg2 and combined treatment groups, implying that both annexin II and Reg- 2 protein may reduce TNF- $\alpha$ expression and release. Moreover, Reg- 2 treatment had a better effect than annexin II treatment. As previous reports demonstrated that microinjection of TNF- $\alpha$ into the brain and spinal cord elicited a response of CNS macrophages and neutrophil recruitment [40], the inhibition of TNF- $\alpha$ may also contribute to the beneficial anti-inflammatory effects of our agents.

Previous findings demonstrated that annexin I may inhibit the expression and release of inflammatory cytokines such as TNF- $\alpha$ and IL-1 $\beta$ and reduce circulating TNF- $\alpha$ and IL-1 $\beta$ levels $[20,46]$. Our results imply that annexin II may also have similar effects. Although there was no direct proof that Reg- 2 affected TNF- $\alpha$ expression, several studies demonstrated the anti-inflammatory role of one neurotrophic factor, CNTF, by inhibiting the production and counterbalancing the effects of TNF$\alpha$ [47-48]. Reg-2 is thought to be an intermediate in the survival signaling pathway of the CNTF-related cytokines [26]. Our previous study also confirmed that a high dose of Reg-2 downregulates TNF- $\alpha$ expression similar 
Fig. 17. Annexin II and Reg-2 treatment can reduce the loss of injured neurons in transected spinal cord at both 7 and 42 days after injury. Cresyl violet (Nissl) staining, transverse section through injury epicenter. Bar $=200 \mu \mathrm{m}$. a-d Images taken at 7 days after injury. a Vehicle control group. b Annexin II-treated group. c Reg-2-treated group. d A+R-treated group. e-h Images taken at 42 days after injury. e Vehicle control group. f Annexin II-treated group. g Reg-2-treated group. h A+R-treated group.

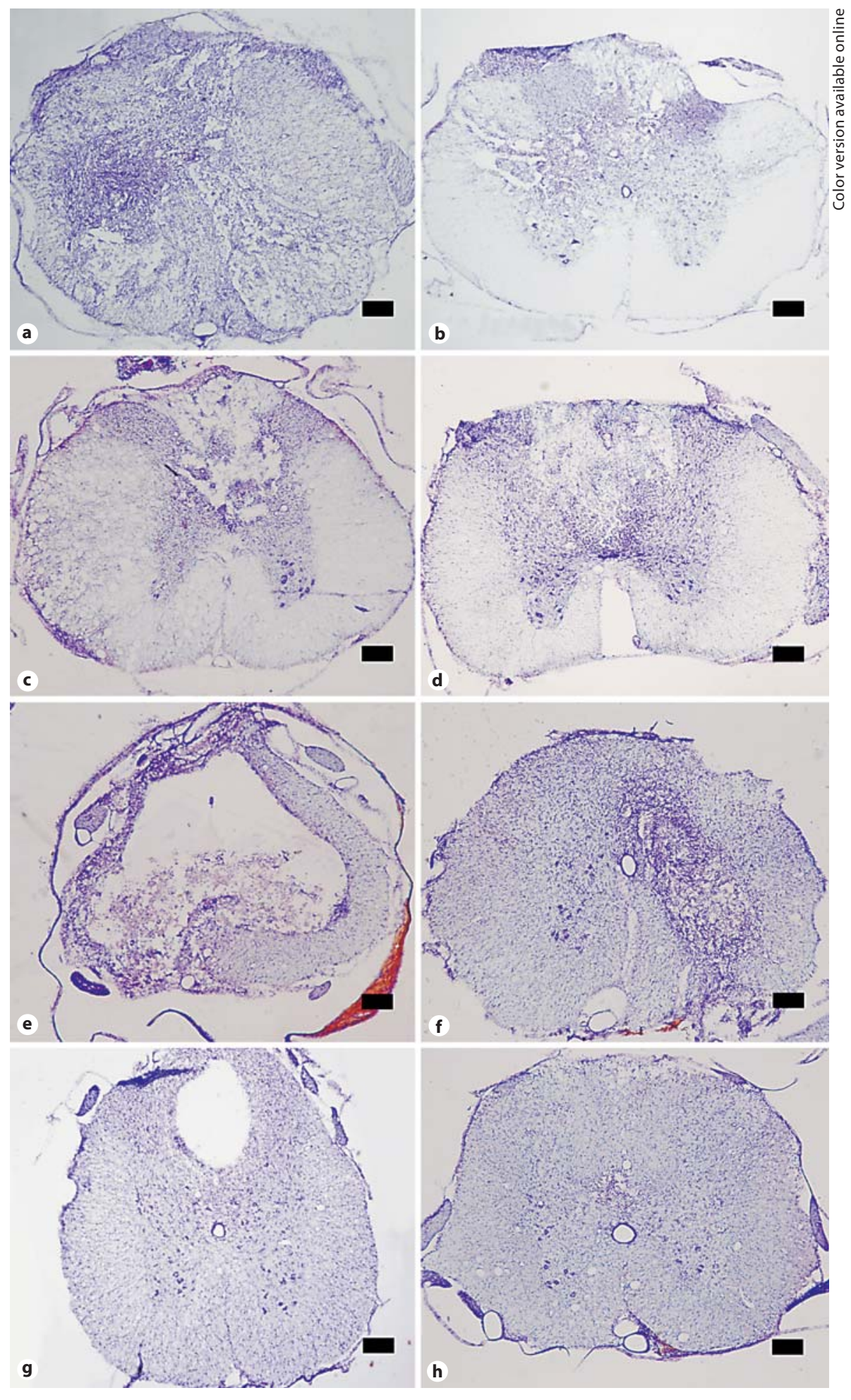


Fig. 18. Annexin II and Reg-2 treatment can inhibit apoptosis and reduce apoptosis of neural cells marked by caspase- 3 immunoreaction. Hematoxylin counterstain. Bar $=100 \mu \mathrm{m}$. a-d Images taken at 7 days after injury. a Vehicle control group. b Annexin II-treated group. c Reg-2-treated group. d A+R-treated group. Amount of caspase-3 IR cells in each group at 7 days (e) and 42 days (f) following SCI. ${ }^{*}$ p $<0.01$ vs. vehicle control; ${ }^{\#} \mathrm{p}<0.01$ vs. annexin II-treated group; ${ }^{\$} \mathrm{p}<0.05$ vs. Reg-2-treated group.
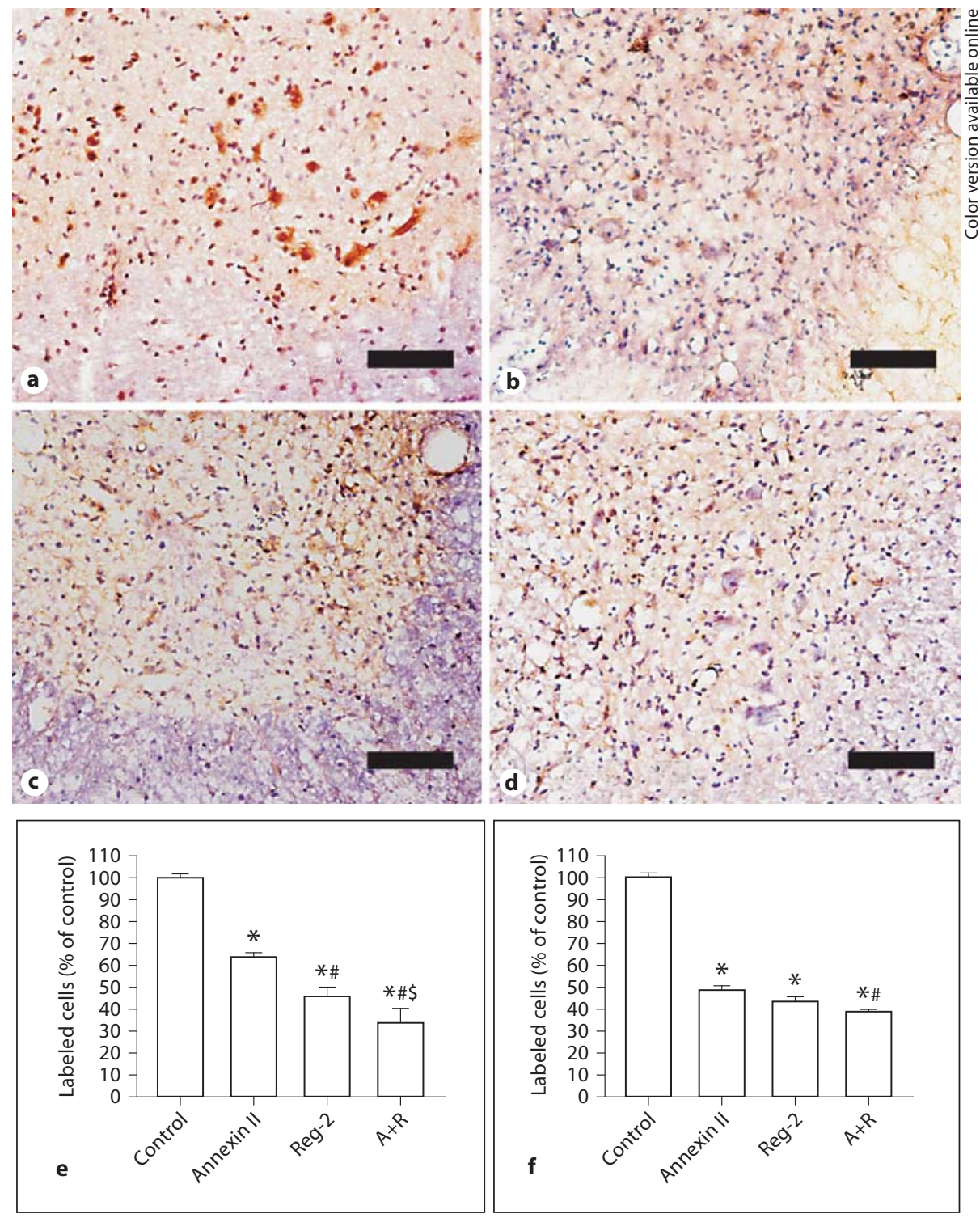

to CNTF [33]; thus, we suggest that Reg-2 exerts anti-inflammatory effects via the same pathway of its upstream agent CNTF.

Our regression analyses showed that the decrease in inflammation area correlated well with the increase in the area of white matter sparing, and the area of white matter sparing further correlated well with the improvement in BBB scores. That may, at least in part, explain the neuroprotective and functional recovery effects of annexin II and Reg-2.

SCI-induced cell death, particularly apoptosis in secondary injury stage, was the main cause of neuronal loss [49-50]. Accordingly, the prevention of cellular apoptot- ic wave will gain tremendous value to functional recovery following SCI. The active caspase- 3 is an enzyme expressed after SCI and critically involved in the execution of the mammalian apoptotic cell death program. A remarkable decrease in caspase- 3 expression, with a visible decline in apoptosis cells, was confirmed in treated groups. Our findings are consistent with previous studies on the antiapoptotic effects of Reg-2 protein on pancreatic cell lines [21-23], which proposed that Reg-2 might also play a role as a neurotrophic factor in the regeneration process of injured neural cells. As for annexin II, the antiapoptotic effects may also contribute to its anti-inflammatory actions. The significant increase in neuron 


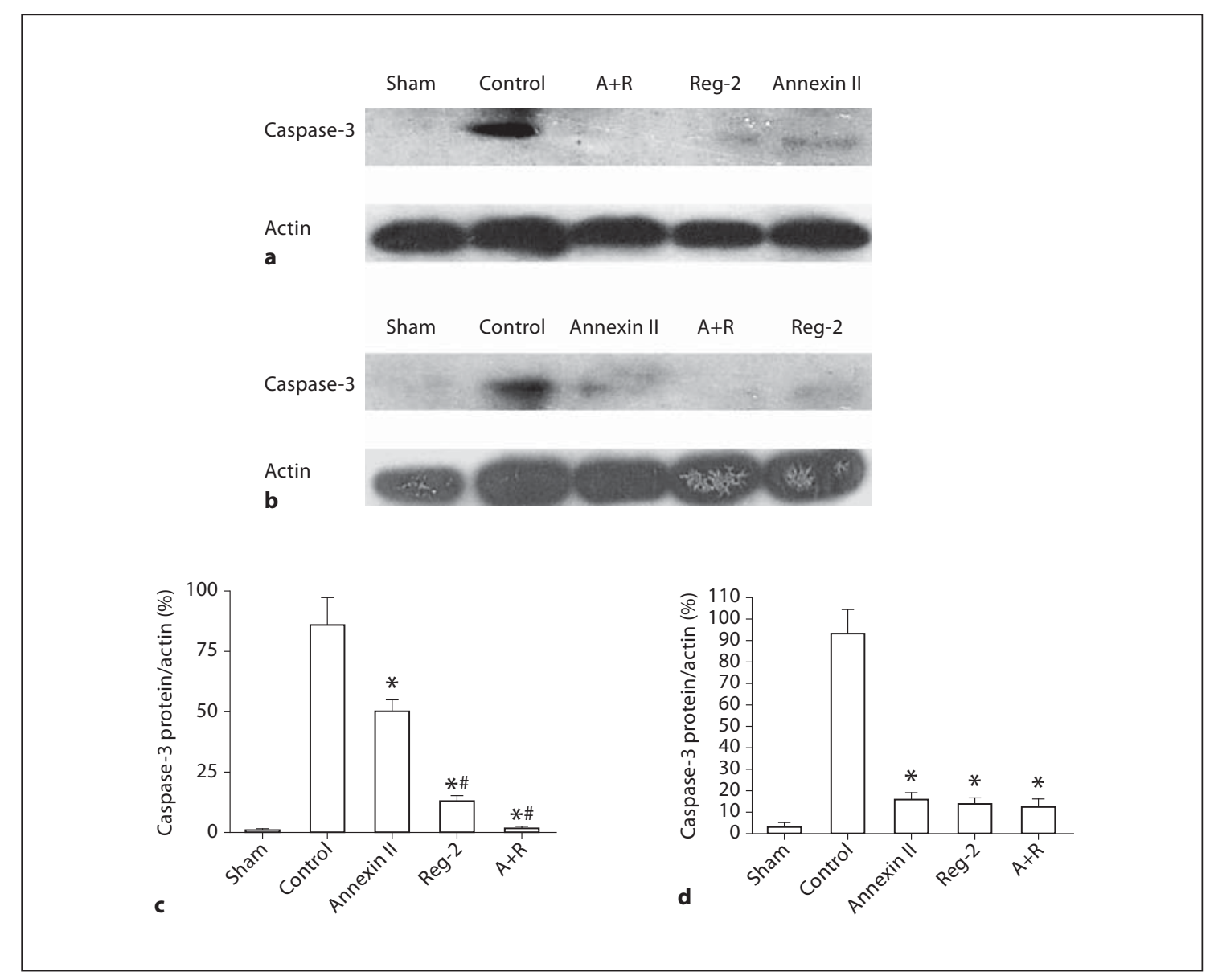

Fig. 19. Analysis of Western blots for caspase-3 expression profile. The level of caspase-3 expression declined remarkably after annexin II and Reg-2 application as compared with vehicle control at 7 days (a) and 42 days after injury (b). Level of caspase-3 expression revealed by densitometric analysis of Western blotting bands at 7 days (c) and 42 days (d) following SCI. Mean ratio was recorded as densitometric ratio vs. $\beta$-actin. Column graph depicts the mean densitometric value of caspase-3: $\beta$-actin. ${ }^{*} \mathrm{p}<0.01$ vs. vehicle control. ${ }^{*} \mathrm{p}<0.01 \mathrm{vs}$. annexin II-treated group.

survival evaluated by cell counting in each treated group further confirmed the neuroprotective effects of our agents.

The secondary injury following SCI could induce severe tissue damage. In the last pathological stage, large cystic cavity appeared in the parenchyma of lesion epicenters as well as the adjacent rostral/caudal regions of the spinal cord. The amount of spared tissue in injury site closely correlates with the residual neurological function $[35,51]$. Our observations indicate that treatment with annexin II, Reg-2 and combined drugs reduced the cavity area to 39,30 and $28 \%$ of the control group, respectively. The reductions in lesion area in these groups were accompanied by a remarkable increase in spared white matter surrounding the lesion epicenter. It is well known that the oligodendrocytes are highly vulnerable in aggravated microenvironment of injured spinal cord. At chronic stages of SCI, a large number of oligodendrocytes undergo apoptosis [49, 52], leading to denudement of axons and deterioration of their conductive abilities, exacerbating the decline in function [37]. In all treated groups, significant decreases in demyelination areas, evidenced by a faint LFB staining, were detected at both 7 and 42 days following SCI, as might be ascribed to the inhibition of oligodendrocyte apoptosis and associations with preservation of normal tissue.

The increase in spared white matter will rationally accompany the increase in spared axons. At 6 weeks after 
Fig. 20. Annexin II and Reg-2 treatment inhibited TNF- $\alpha$ expression within injured neural cells as detected by TNF- $\alpha$ immuno-reaction. Hematoxylin counterstain. Bar $=100 \mu \mathrm{m}$. a-d Images taken at 7 days after injury. a Vehicle control group. b Annexin II-treated group. c Reg-2-treated group. $\mathbf{d} \mathrm{A}+\mathrm{R}$-treated group. Amount of TNF- $\alpha$ IR cells (\% of vehicle control) in each group was calculated at 7 days (e) and 42 days (f) following SCI. ${ }^{*} \mathrm{p}<0.01$ vs. vehicle control; ${ }^{\#} \mathrm{p}<0.05$ vs. annexin IItreated group; ${ }^{\#} \mathrm{p}<0.01$ vs. annexin IItreated group.
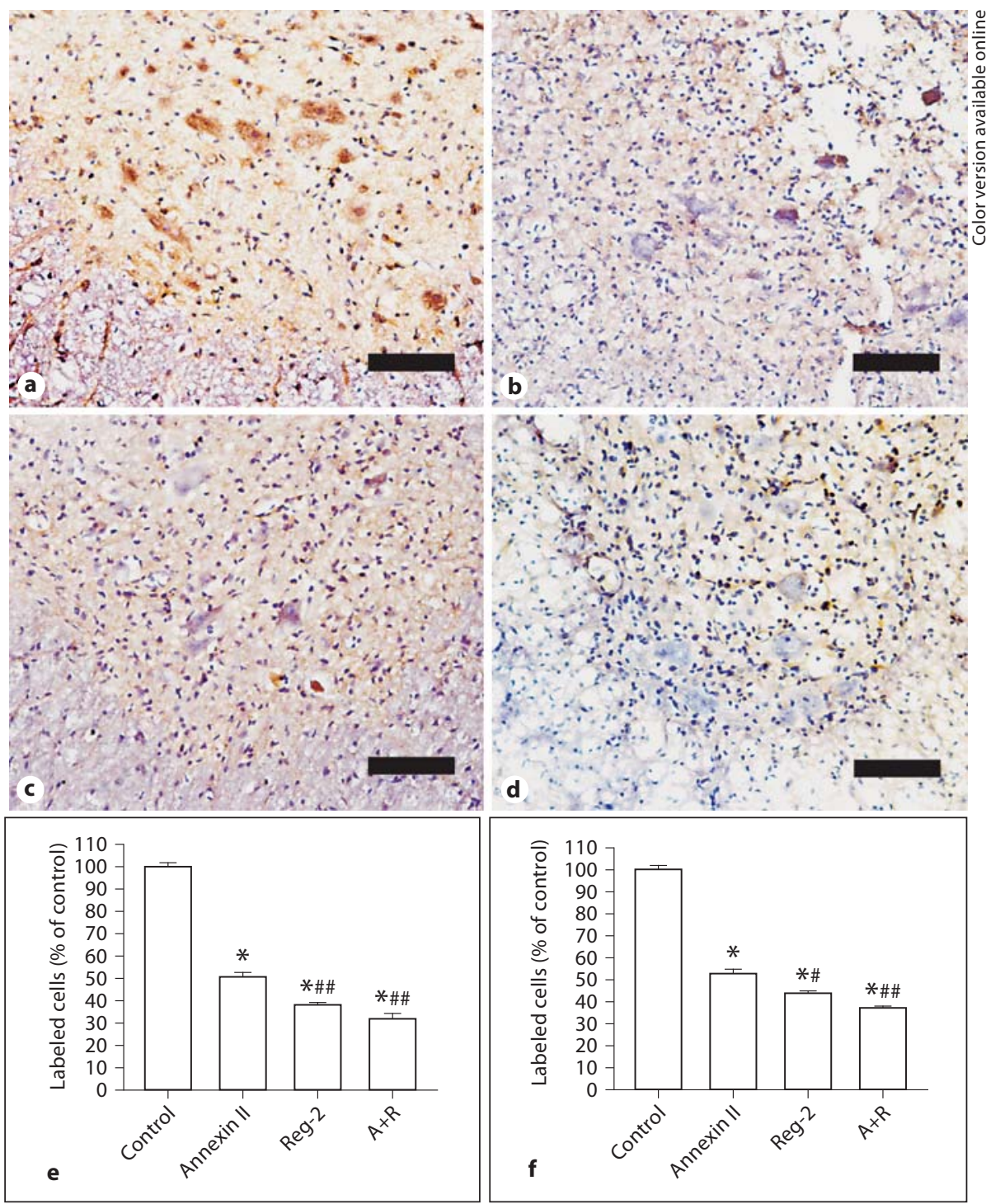

injury, numerous NF-IR axon profiles were found in the area directly adjacent to the cavity borders, indicating the presence of intact axons within spared tissue. Much more spared NF-IR fibers were found in the annexin II- and Reg-2-treated groups than in the vehicle control, implying an increase in axonal sparing in these groups. Eager's silver staining also exhibited large axon loss area as well as black degenerated axons within vehicle control. Similarly, much more intact axons were kept, and numerous axons penetrated through the injury epicenter in the treated groups.

FG retrograde tracing demonstrated that the enhancement of white matter sparing was accompanied by an increase in the sparing of propriospinal axons and long de- scending/ascending supraspinal axons. A 2- to 3-fold increase in the number of FG-labeled propriospinal neurons in the $\mathrm{C}_{6}$ and $\mathrm{T}_{5}$ cord segments was identified in the annexin II and Reg-2 treatment groups based on the representative cervical and thoracic segments where axons form propriospinal projections descending to the spinal cord caudal to the injury. In all treated groups, an evident increase in the number of labeled neurons in several brainstem nuclei as well as in the Ctx-HL was shown, indicating the increase in spared long distance ascending axons and descending axons. The preserving effects of annexin II and Reg-2 protein on the neurons of rubrospinal and corticospinal descending tracts may benefit functional recovery. As more FG-labeled cells were detected 


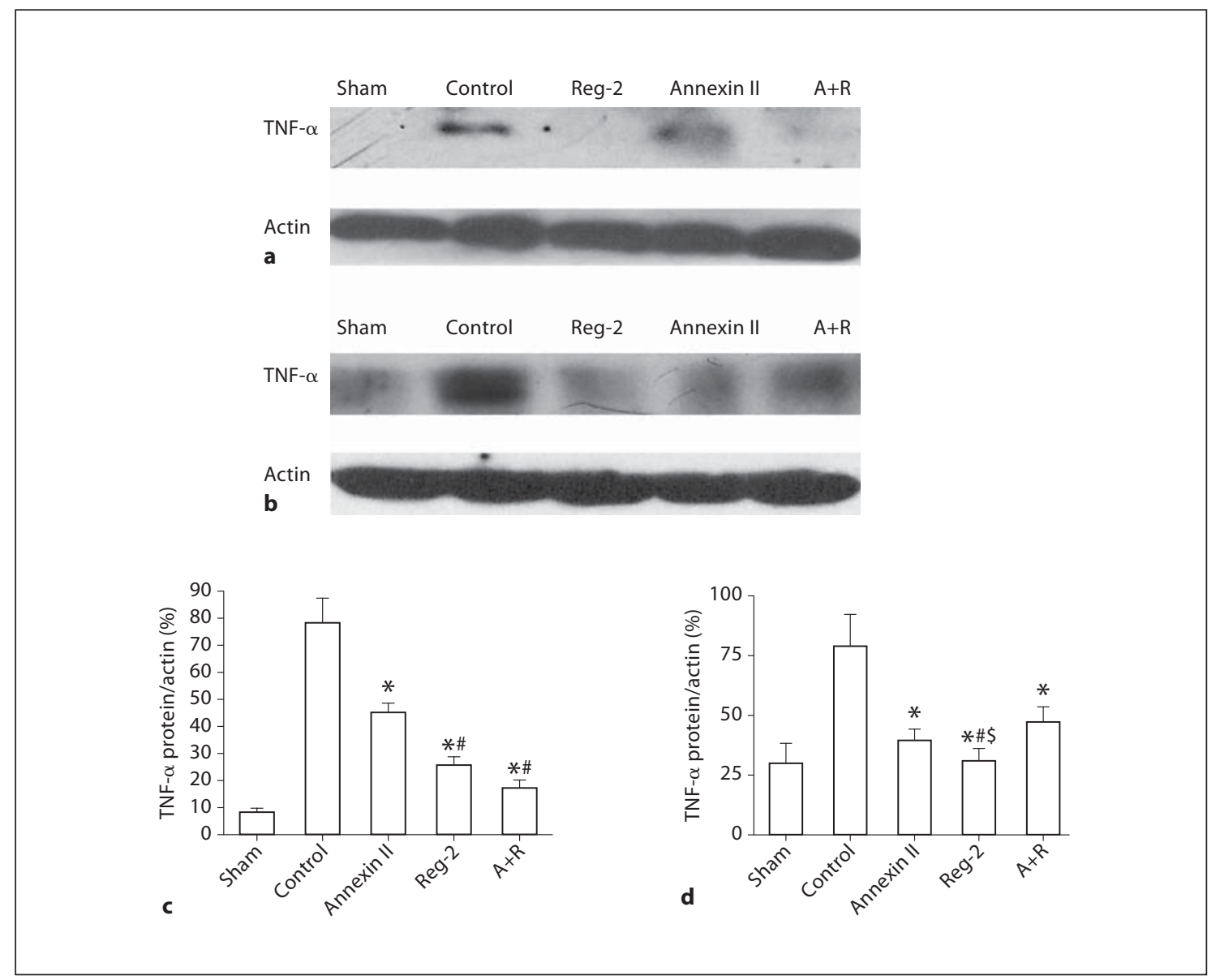

Fig. 21. Analysis of Western blots for TNF- $\alpha$ expression profile. The level of TNF- $\alpha$ expression declined remarkably after annexin II and Reg-2 application as compared with the vehicle control at 7 days (a) and 42 days (b) after injury. Densitometric analysis of Western blot bands was used to compare the level of TNF- $\alpha$ expression at 7 days (c) and 42 days (d) following SCI (mean \pm SD). Mean ratio was recorded as densitometric ratio vs. $\beta$ actin. Column graph depicts the mean densitometric value of TNF- $\alpha$ : $\beta$-actin. ${ }^{*} \mathrm{p}<0.01$ vs. vehicle control; ${ }^{\#} \mathrm{p}<0.05$ vs. annexin II-treated group; ${ }^{\$} \mathrm{p}<0.05$ vs. A+R-treated group.

in $\mathrm{RN}$ and Ctx-HL of Reg-2 protein and combined treatment groups, a better motor functional recovery achieved in these two groups could be deduced.

Reactive gliosis has been considered as a major impediment for SCI repair. Our observation revealed that annexin II treatment inhibited GFAP expression at a late stage of SCI. This effect was similar to a previous observation on annexin I [20], and implied that annexin II may also mediate its neuroprotective effects, at least in part, by inhibiting reactive astrogliosis after SCI. Although the Reg-2 treatment showed no inhibitive effects on reactive astrogliosis, there was also no evident effect of Reg-2 on inducing reactive gliosis like its upstream agent CNTF [32].

Effects of Annexin II and Reg-2 in in vivo Injury Models
Except for these favorable influences, our treatments also activated the expression of neurite growth-promoting factors GAP-43. The expression of GAP-43 was initially elevated after injury [53], while the application of annexin II and Reg-2 protein could further promote and maintain this upregulation at different time windows from very early to last pathophysiologic stage of SCI, which implies an increased regenerative capacity of injured neural cells [54]. Our results also demonstrated that the Reg-2 protein could have better neurite growth-promoting effects than annexin II.

Taken together, all the effects of our treatments, including the alleviation of inflammatory reaction, inhibi- 

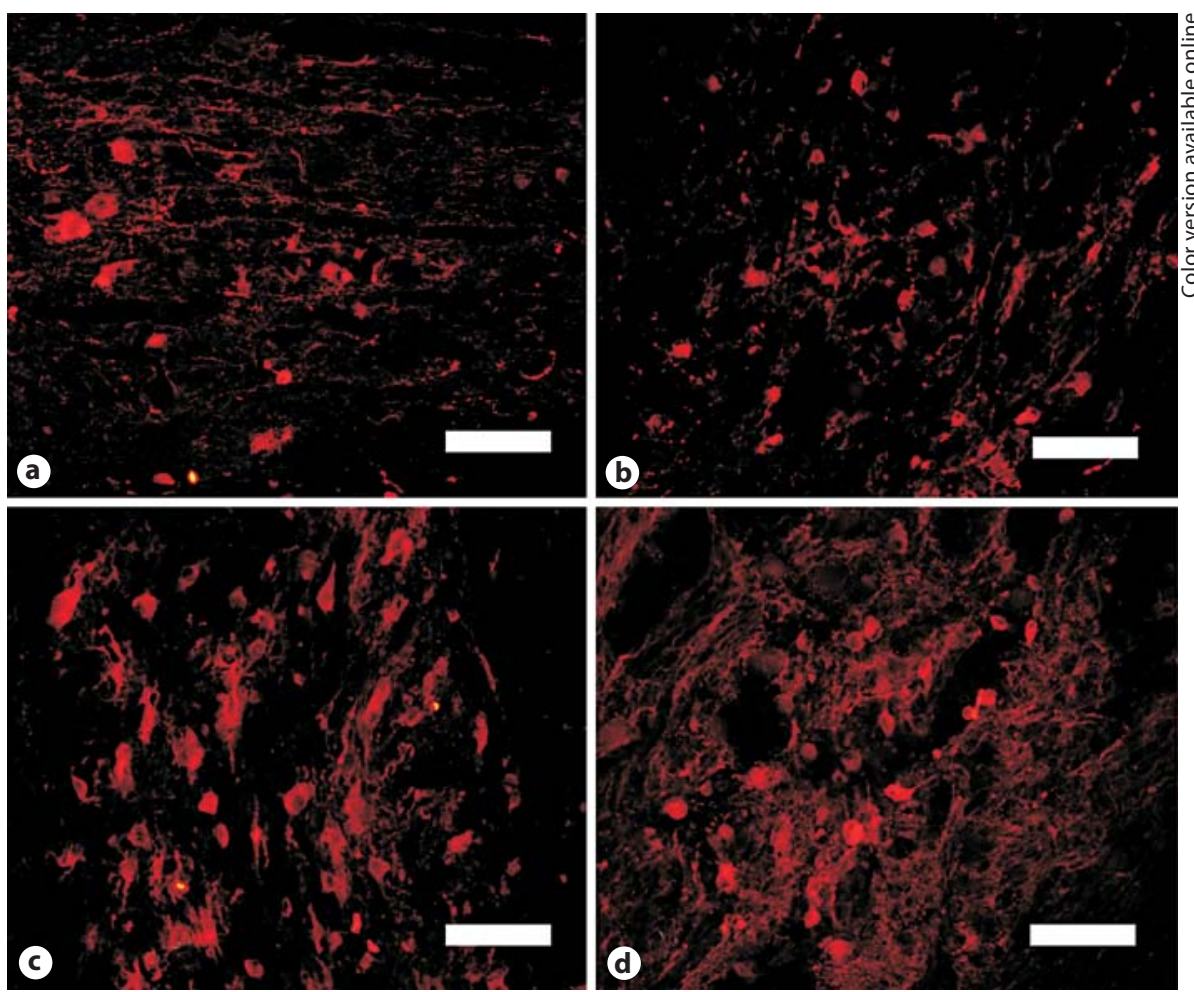

Fig. 22. Annexin II and Reg-2 treatment improved GAP-43 expression within injured neurons. TRITC-conjugated GAP43 immunofluorescent staining, horizontal section. Bar $=100 \mu \mathrm{m}$. a-d Images taken at 7 days after injury. a Vehicle control group. b Annexin II-treated group. c Reg2-treated group. d A+R-treated group. Amount of GAP-43 IR cells (\% of vehicle control) in each group at 7 days (e) and 42 days (f) following SCI. ${ }^{*} \mathrm{p}<0.01$ vs. vehicle control; ${ }^{*} \mathrm{p}<0.01$ vs. annexin II-treated group; ${ }^{\$} \mathrm{p}<0.05$ vs. Reg-2-treated group.
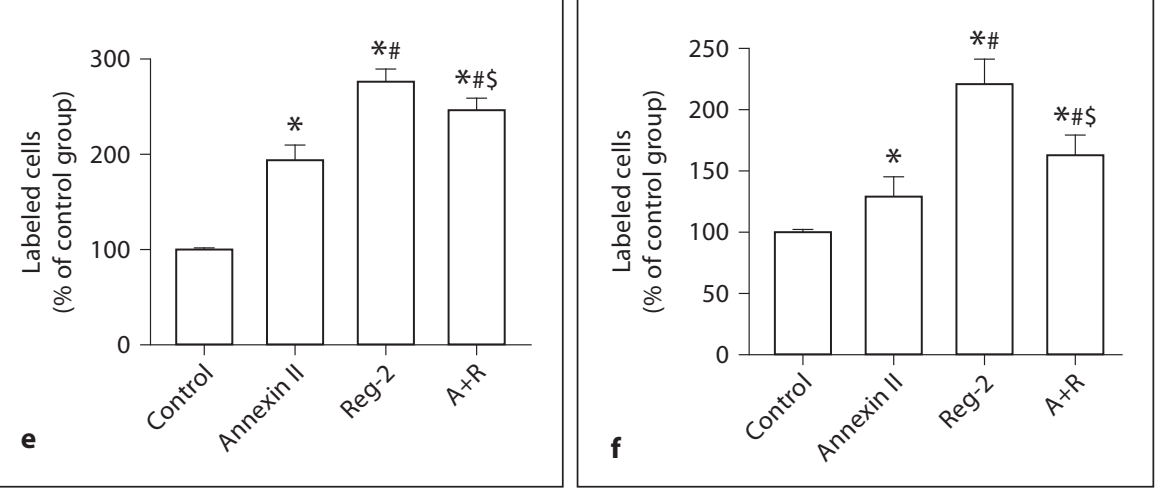

tion of neuronal apoptosis and demyelination, increase in white matter sparing area, preservation of intact axons, stimulation of axonal regeneration, protection of propriospinal axons and long descending/ascending supraspinal axons, may all contribute to the improvement of functional recovery of injured animals. Thereby, the Reg2- and annexin II-treated groups all gained better BBB scores compared with vehicle control at late pathological stage of 6 weeks after SCI. The Reg-2 and combined treatment groups generally have better functional recovery than the annexin II-treated group, which could be explained by the fact that the main effect of annexin II is to alleviate inflammatory reactions and ameliorate the mi- croenvironment of the injury site. Besides targeting the inflammatory mechanism, Reg-2 may also exert neurotrophic effects on injured neurons, which resembles the effects of CNTF. Increased expression of annexin II and Reg-2 following CNS injury and disease may represent an inherent protective mechanism to prevent further damage caused by secondary injury.

Although our drug delivery persisted only for 7 days, the neuroprotective effects could be observed at 6 weeks after injury, which indicates that the neurotrophic treatments had lasting effects even when terminated after one week. 


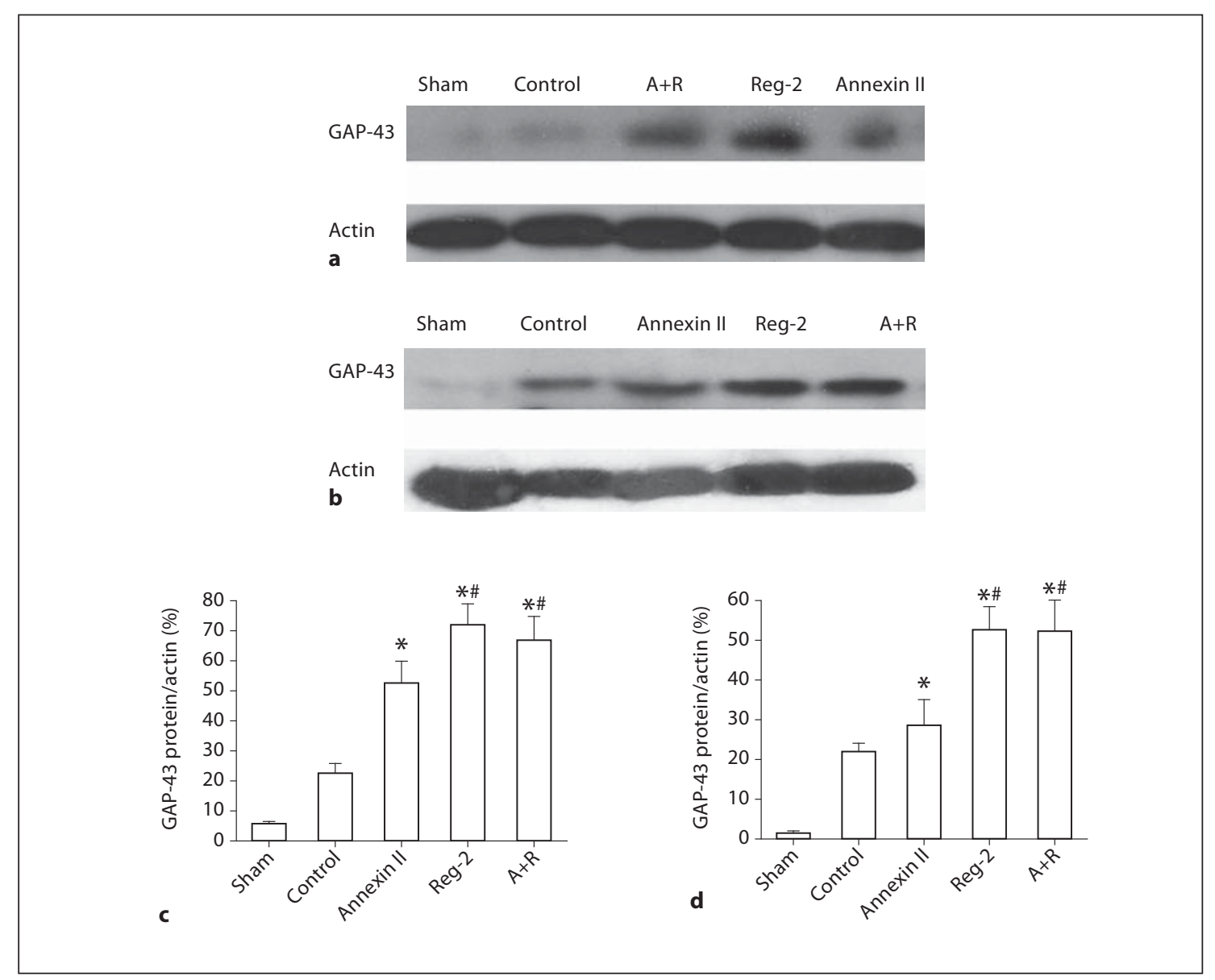

Fig. 23. Analysis of Western blots for GAP-43 expression profile. The level of GAP-43 expression declined remarkably after annexin II and Reg-2 application as compared with the vehicle control at 7 days (a) and 42 days (b) after injury. Densitometric analysis of Western blot bands was used to compare the level of GAP-43 expression at 7 days (c) and 42 days (d) following SCI. ${ }^{*} \mathrm{p}<0.01$ vs. vehicle control; ${ }^{\#} \mathrm{p}<0.01$ vs. annexin II-treated group.

In our study, combined treatment had no better effects than single treatment. Although annexin II showed better anti-inflammatory and antireactive gliosis actions, and Reg-2 had more evident effects on promoting neural regeneration, both of our agents may exert neuroprotective effects with partially overlapping mechanisms. Therefore, the combination of different innovative factors to target different pathways of neurotrophic cytokines should be useful in the search for new therapeutic methods for SCI and other CNS diseases. Experiments along these clues are currently in progress in our laboratory.

\section{Acknowledgments}

This work was supported by the National Natural Science Foundation of China, grant No. 30600192, Science Foundation of Chinese Universities, 2009QNA7014, and Foundation of Zhejiang Province Education, grant No. Y200908553 (to S.H.). 


\section{References}

1 Hamre KM, Chepenik KP, Goldowitz D: The annexins: specific markers of midline structures and sensory neurons in the developing murine central nervous system. J Comp Neurol 1995;352:421-435.

-2 Naciff JM, Kaetzel MA, Behbehani MM, Dedman JR: Differential expression of annexins I-VI in the rat dorsal root ganglia and spinal cord. J Comp Neurol 1996;368:356370 .

3 Johnson MD, Jimmy MK, William OW Jr, Pepinsky RB: Lipocortin-1 immunoreactivity in the normal human central nervous system and lesions with astrocytosis. Am J Clin Pathol 1989;92:424-429.

4 Elderfield AJ, Bolton C, Flower RJ: Lipocortins 1 (annexin I) immunoreactivity in the spinal cord of Lewis rats with acute experimental allergic encephalomyelitis. J Neurol Sci 1993;119:146-153.

5 Flower RJ, Rothwell NJ: Lipocortin-1: cellular mechanisms and clinical relevance. Trends Pharmacol Sci 1994;15:71-76.

-6 Perretti M: Lipocortin-derived peptides. Biochem Pharmacol 1994;47:931-938.

7 Raynal P, Pollard HB: Annexins: the problem of assessing the biological role for a gene family of multifunctional calcium- and phospholipid-binding proteins. Biochim Biophys Acta 1994;1197:63-93.

$>8$ Morgan RO, Fernandez MP: Annexin gene structures and molecular evolutionary genetics. Cell Mol Life Sci 1997;53:508-515.

9 Pepinsky RB, Tizard R, Mattaliano RJ, Sinclair LK, Miller GT, Browning JL, Chow EP, Burne C, Huang KS, Pratt D, Wachter L, Hession C, Frey AZ, Wallner B: Five distinct calcium and phospholipid binding proteins share homology with lipocortin I. J Biol Chem 1988;263:10799-10811.

-10 Cirino G, Peers SH, Flower RJ, Browning JL, Pepinsky RB: Human recombinant lipocortin 1 has acute local anti-inflammatory properties in the rat paw edema test. Proc Natl Acad Sci USA 1989;86:3428-3432.

$\checkmark 11$ Errasfa M, Russo-Marie F: A purified lipocortin shares the anti-inflammatory effect of glucocorticosteroids in vivo in mice. $\mathrm{Br} J$ Pharmacol 1989;97:1051-1058.

-12 Perretti M, Ahluwalia A, Harris JG, Goulding NJ, Flower RJ: Lipocortin-1 fragments inhibit neutrophil accumulation and neutrophil-dependent edema in the mouse. A qualitative comparison with an anti-CD11b monoclonal antibody. J Immunol 1993;151: 4306-4314.

>13 Zhang KH, Xiao HS, Lu PH, Shi J, Li GD, Wang YT, Han S, Zhang FX, Lu YJ, Zhang X, $\mathrm{Xu} X \mathrm{XM}$ : Different gene expression after complete spinal cord transection in adult rats: an analysis focused on a subchronic post-injury stage. Neuroscience 2004;128:375-388.
14 Liu N, Han S, Lu PH, Xu XM: Upregulation of annexins I, II and V following traumatic spinal cord injury in adult rats. J Neurosci Res 2004;77:391-401.

15 Flower RJ: Lipocortin. Prog Clin Biol Res 1990;349:11-25.

16 Bonventre JV: Roles of phospholipases $\mathrm{A}_{2}$ in brain cell and tissue injury associated with ischemia and excitotoxicity. J Lipid Mediat Cell Signal 1997;14:15-23.

17 Farooqui AA, Yang HC, Rosenberger TA, Horrocks LA: Phospholipase $\mathrm{A}_{2}$ and its role in brain tissue. J Neurochem 1997;69:889901.

18 Takei N, Ohsawa K, Imai Y, Nakao H, Iwasaki A, Kohsaka S: Neurotrophic effects of annexin $\mathrm{V}$ on cultured neurons from embryonic rat brain. Neurosci Lett 1994;171:5962.

19 Mizuno H, Asai K, Fujita K, Uemura K, Wada Y, Moriyama A, Ogawa H, Kimura S, Kato T: Neurotrophic action of lipocortin 1 derived from astrocytes on cultured rat cortical neurons. Brain Res Mol Brain Res 1998; 60:28-39.

20 Liu NK, Zhang YP, Han S, Pei J, Xu LY, Lu $\mathrm{PH}$, Shields $\mathrm{CB}, \mathrm{Xu} \mathrm{XM}$ : Annexin A1 reduces inflammatory reaction and tissue damage through inhibition of phospholipase $\mathrm{A}_{2}$ activation in adult rats following spinal cord injury. J Neuropathol Exp Neurol 2007;66: 932-943.

-21 Iovanna J, Orelle B, Keim V, Dagorn JC: Messenger RNA sequence and expression of rat pancreatitis-associated protein, a lectin-related protein overexpressed during acute experimental pancreatitis. J Biol Chem 1991; 266:24664-24669.

22 Orelle B, Keim V, Masciotra L, Dagorn JC, Iovanna JL: Human pancreatitis-associated protein. Messenger RNA cloning and expression in pancreatic diseases. J Clin Invest 1992;90:2284-2291.

23 Ortiz EM, Dusetti NJ, Vasseur S, Malka D, Bödeker H, Dagorn JC, Iovanna JL: The pancreatitis-associated protein is induced by free radicals in AR4-2J cells and confers cell resistance to apoptosis. Gastroenterology 1998;114:808-816.

24 Livesey FJ, O’Brien JA, Li M, Smith AG, Murphy LJ, Hunt SP: A Schwann cell mitogen ac companying regeneration of motor neurons. Nature 1997;390:614-618.

25 De la Monte SM, Ozturk M, Wands JR: Enhanced expression of an exocrine pancreatic protein in Alzheimer's disease and the developing human brain. J Clin Invest 1990;86: 1004-1013.

26 Nishimune H, Vasseur S, Wiese S, Birling MC, Holtmann B, Sendtner M, Iovanna JL, Henderson CE: Reg-2 is a motoneuron neurotrophic factor and a signalling intermediate in the CNTF survival pathway. Nat Cell Biol 2000;2:906-914.
27 Averill S, Davis DR, Shortland PJ, Priestley JV, Hunt SP: Dynamic pattern of reg-2 expression in rat sensory neurons after peripheral nerve injury. J Neurosci 2002;22:74937501.

28 Averill S, Inglis JJ, King VR, Thompson SW, Cafferty WB, Shortland PJ, Hunt SP, Kidd BL, Priestley JV: Reg-2 expression in dorsal root ganglion neurons after adjuvant-induced monoarthritis. Neuroscience 2008; 155:1227-1236.

29 Fang M, Huang JY, Ling SC, Rudd JA, Yew DT, Han S: Effects of Reg-2 on survival of spinal cord neurons in vitro. Anat Rec 2010; 293:264-276.

30 Han S, Zhang KH, Lu PH, Xu XM: Effects of annexins II and $\mathrm{V}$ on the survival of neurons and astrocytes in vitro. Acta Pharmacol Sin 2004;25:602-610.

31 Nakashima S, Arnold SA, Mahoney ET, Sithu SD, Zhang YP, D’Souza SE, Shields CB, Hagg T: Small-molecule protein tyrosine phosphatase inhibition as a neuroprotective treatment after spinal cord injury in adult rats. J Neurosci 2008;28:7293-7303.

32 Ye J, Cao L, Cui R, Huang A, Yan Z, Lu C, He $\mathrm{C}$ : The effects of ciliary neurotrophic factor on neurological function and glial activity following contusive spinal cord injury in the rats. Brain Res 2004;997:30-39.

-33 Fang M, Wang J, Huang JY, Ling SC, Rudd JA, Hu ZY, Yew DT, Han S: The neuroprotective effects of Reg-2 following spinal cord transection injury. Anat Rec 2011;294:2445.

-34 Basso DM, Beattie MS, Bresnahan JC: Graded histological and locomotor outcomes after spinal cord contusion using the NYU weight-drop device versus transection. Exp Neurol 1996;139:244-256.

>35 Basso DM, Beattie M, Bresnahan JC: A sensitive and reliable locomotor rating scale for open field testing in rats. J Neurotrauma 1995; 12:1-21.

36 Eager RP: Selective staining of degenerating axons in the central nervous system by a simplified silver method: spinal cord projections to external cuneate and inferior olivary nuclei in the cat. Brain Res 1970;22:137-141.

37 Profyris C, Cheema SS, Zang D, Azari MF, Boyle K, Petratos S: Degenerative and regenerative mechanisms governing spinal cord injury. Neurobiol Dis 2004; 15:415-436.

38 Carlson GD, Gorden C: Current developments in spinal cord injury research. Spine J 2002;2:116-128.

-39 Houle JD, Tessler A: Repair of chronic spinal cord injury. Exp Neurol 2003;82:247-260.

40 Donnelly DJ, Popovich PG: Inflammation and its role in neuroprotection, axonal regeneration and functional recovery after spinal cord injury. Exp Neurol 2008;209:378388 . 
-41 Shuman SL, Bresnahan JC, Beattie MS: Apoptosis of microglia and oligodendrocytes after spinal cord contusion in rats. J Neurosci Res 1997;50:798-808.

-42 Popovich PG, Guan Z, Wei P, Huitinga I, van Rooijen N, Stokes BT: Depletion of hematogenous macrophages promotes partial hindlimb recovery and neuroanatomical repair after experimental spinal cord injury. Exp Neurol 1999;158:351-365.

-43 Popovich PG, Guan Z, McGaughy V, Fisher L, Hickey WF, Basso DM: The neuropathological and behavioral consequences of intraspinal microglial/macrophage activation. J Neuropathol Exp Neurol 2002;61:623-633.

-44 Gris D, Marsh DR, Oatway MA, Chen Y, Hamilton EF, Dekaban GA, Weaver LC: Transient blockade of the CD11d/CD18 integrin reduces secondary damage after spinal cord injury, improving sensory, autonomic, and motor function. J Neurosci 2004;24: 4043-4051.

45 Inukai T, Uchida K, Nakajima H, Yayama T, Kobayashi S, Mwaka ES, Guerrero AR, Baba $\mathrm{H}$ : Tumor necrosis factor-alpha and its receptors contribute to apoptosis of oligodendrocytes in the spinal cord of spinal hyperostotic mouse (twy/twy) sustaining chronic mechanical compression. Spine 2009;34: 2848-2857.
46 De Coupade C, Ajuebor MN, Russo-Marie F, Perretti M, Solito E: Cytokine modulation of liver annexin 1 expression during experimental endotoxemia. Am J Pathol 2001;159: 1435-1443.

47 Meazza C, Di Marco A, Fruscella P, Gloaguen I, Laufer R, Sironi M, Sipe JD, Villa P, Romano M, Ghezzi P: Centrally mediated inhibition of local inflammation by ciliary neurotrophic factor. Neuroimmunomodulation 1997;4:271-276.

48 Linker RA, Mäurer M, Gaupp S, Martini R, Holtmann B, Giess R, Rieckmann P, Lassmann H, Toyka KV, Sendtner M, Gold R: $\mathrm{CNTF}$ is a major protective factor in demyelinating CNS disease: a neurotrophic cyto kine as modulator in neuroinflammation. Nat Med 2002;8:620-624.

49 Crowe MJ, Bresnahan JC, Shuman SL, Masters JN, Beattie MS: Apoptosis and delayed degeneration after spinal cord injury in rats and monkeys. Nat Med 1997;3:73-76.
50 Liu XZ, Xu XM, Hu R, Du C, Zhang SX, McDonald JW, Dong HX, Wu YJ, Fan GS, Jacquin MF, Hsu CY, Choi DW: Neuronal and glial apoptosis after traumatic spinal cord injury. J Neurosci 1997;17:5395-5406.

51 Rosenberg LJ, Wrathall JR: Quantitative analysis of acute axonal pathology in experimental spinal cord contusion. J Neurotrauma 1997; 14:823-838.

52 Warden P, Bamber NI, Li H, Esposito A, Ahmad KA, Hsu CY, Xu XM: Delayed glial cell death following Wallerian degeneration in white matter tracts after spinal cord dorsal column cordotomy in adult rats. Exp Neurol 2001;168:213-224.

53 Kobayashi NR, Fan DP, Giehl KM, Bedard AM, Wiegand SJ, Tetzlaff W: BDNF and NT$4 / 5$ prevent atrophy of rat rubrospinal neurons after cervical axotomy, stimulate GAP43 and Talpha1-tubulin mRNA expression, and promote axonal regeneration. J Neurosci 1997;17:9583-9595.

54 Xu JJ, Chen EY, Lu CL, He C: Recombinant ciliary neurotrophic factor promotes nerve regeneration and induces gene expression in silicon tube-bridged transected sciatic nerves in adult rats. J Clin Neurosci 2009;16: 812-817. 